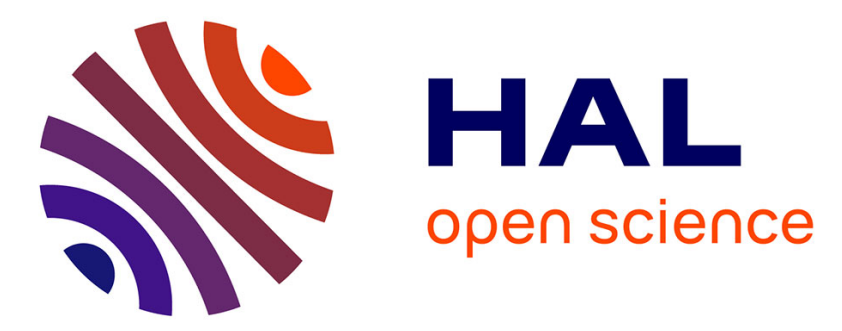

\title{
Comparitive study on structural, magnetic and spectroscopic properties of four new copper(II) coordination polymers with 4'-substituted terpyridine ligands
}

D. Toledo, A. Vega, N. Pizarro, R. Baggio, O. Peña, T. Roisnel, J.-Y. Pivan, Y. Moreno

\section{To cite this version:}

D. Toledo, A. Vega, N. Pizarro, R. Baggio, O. Peña, et al.. Comparitive study on structural, magnetic and spectroscopic properties of four new copper(II) coordination polymers with 4'-substituted terpyridine ligands. Journal of Solid State Chemistry, 2017, 253, pp.78-88. 10.1016/j.jssc.2017.05.017 . hal-01544469

HAL Id: hal-01544469

https://hal-univ-rennes1.archives-ouvertes.fr/hal-01544469

Submitted on 21 Jun 2017

HAL is a multi-disciplinary open access archive for the deposit and dissemination of scientific research documents, whether they are published or not. The documents may come from teaching and research institutions in France or abroad, or from public or private research centers.
L'archive ouverte pluridisciplinaire HAL, est destinée au dépôt et à la diffusion de documents scientifiques de niveau recherche, publiés ou non, émanant des établissements d'enseignement et de recherche français ou étrangers, des laboratoires publics ou privés. 


\title{
COMPARATIVE STUDY ON STRUCTURAL, MAGNETIC AND SPECTROSCOPIC PROPERTIES OF FOUR NEW COPPER(II) COORDINATION POLYMERS WITH 4'-SUBSTITUTED TERPYRIDINE LIGANDS
}

Dominique Toledo, ${ }^{1}$ Andrés Vega, ${ }^{2}$ Nancy Pizarro, ${ }^{2}$ Ricardo Baggio, ${ }^{3}$ Octavio Peña, ${ }^{4}$ Thierry Roisnel, ${ }^{4}$ JeanYves Pivan, ${ }^{4,5}$ Yanko Moreno* ${ }^{2}$

1 Universidad de Concepción, Facultad de Ciencias Químicas, Departamento de Química Analítica e Inorgánica, Concepción, Chile.

${ }^{2}$ Universidad Andres Bello, Dpto. Ciencias Química, Fac. Ciencias Exactas. C.P. 2520000, Viña del Mar, Chile.

${ }^{3}$ Gerencia de Investigación y Aplicaciones, Centro Atómico Constituyentes, Comisión Nacional de Energía Atómica, Buenos Aires, Argentina

${ }^{4}$ Institut des Sciences Chimiques de Rennes, UMR 6226, Université de Rennes-1, Rennes, France.

${ }^{5}$ École Nationale Supérieure de Chimie de Rennes, Rennes, France

* Corresponding author: yanko.moreno@unab.cl

\begin{abstract}
The synthesis and characterization of four copper(II) complexes with different terpyridyl ligands have been carried out, their crystal and molecular structures determined and their magnetic and luminescent properties analyzed. The ligands used in the coordination reactions were 4'-(3-methyl-2-thienyl)-4,2':6',4"-terpyridine (4stpy), -4'-(4-quinolinyl)-4,2':6',4"-terpyridine (4-qtpy), 4'-(4-quinolinyl)-3,2':6',3"-terpyridine (3-qtpy, unreported so far) and 4'-(4-cyanophenyl)-4,2':6',4"-terpyridine (4-cntpy); the reaction of these ligands with $\mathrm{Cu}$ (II)-hexafluoroacetylacetone $\left(\boldsymbol{C u}(\boldsymbol{h f a c a c})_{2}\right)$ gives rise to coordination polymers $\mathrm{Cu}$ (4-stpy)(hfacac) ${ }_{2}$ (I), $\mathrm{Cu}$ (4-qtpy)(hfacac) $)_{2}$ (II), $\mathrm{Cu}$ (3-qtpy)(hfacac) $)_{2}$ (III) and $\mathrm{Cu}$ (4-cntpy)(hfacac) $)_{2}$ (IV). The different location of the nitrogen atom of the outer ring is responsible for the different coordination modes.

The emission spectra of dichloromethane solutions are consistent with dissociation of the complexes; the emission maxima simulate those of the free ligands. The emission of I, III and IV in the solid state is essentially quenched upon complexation with $\mathrm{Cu}(\mathrm{II})$, whereas for compound II an emission at $420 \mathrm{~nm}$ is observed.

The interaction between copper centers has been related with the coplanarity of terpyridine rings. Complexes IIII exhibit a paramagnetic behaviour, while compound IV, with the smallest torsion angle between pyridine moieties, shows an antiferromagnetic behaviour described by a dimeric model, with $J=-4.38 \mathrm{~cm}^{-1}, g=2.06$ and $\rho=0.07$.
\end{abstract}




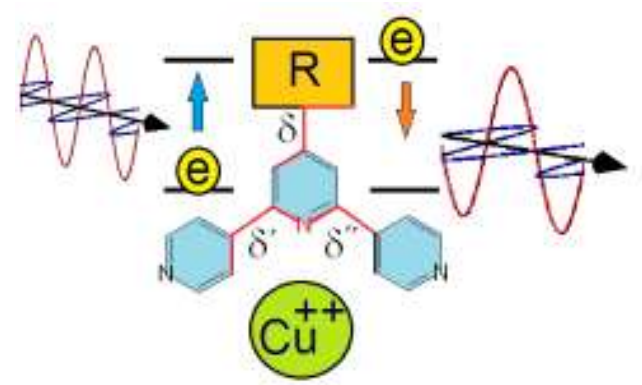

Four copper coordination polymers containing 4'-substituted terpyridine have been synthesized and studied their crystal structures, magnetic and luminescent properties.

Keywords: terpyridine derivatives; copper coordination polymers; magnetic properties; luminescent properties.

\section{Introduction}

The modeling of Coordination Polymers (CPs) and Metal Organic Frameworks (MOF) based on multidentate ligands such as polycarboxylate and N-heterocyclic ligands, has gained increasing attention because of their fascinating architectures and potential applications as functional materials in many fields. ${ }^{1-9}$

The structural diversity, topology and properties of these compounds depend mainly on the selection of their building blocks (metal centers and organic ligands) and the reaction conditions. In search of stable molecular systems with more than one paramagnetic metal center in order to study possible interactions, multidentate ligands with $\mathrm{N}$-donor heterocyclic rings such as $4,2^{\prime}: 6^{\prime}, 4^{\prime \prime}$-terpyridines and 3,2':6',3''-terpyridines have attracted our interest. The one-pot synthetic procedure and the ease of a structural functionalization of the 4'position of the terpyridine ligand, provide additional opportunities to design diverse metal-organic assemblies including multidimensional coordination polymers as well as discrete supramolecular structures. ${ }^{6,10-18}$

The 4'-substituted- 4,2':6',4''-terpyridines and 3,2':6',3''-terpyridine ligands differ from the conventional $2,2^{\prime}: 6$ ',2' '-terpyridine by the positions of N-donors in the outer pyridyl rings. (Scheme 1).

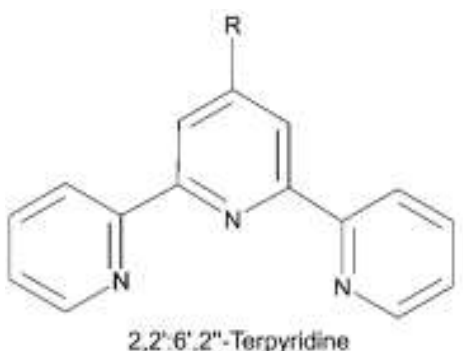

$2,2^{\prime} \cdot 6^{\prime}, 2^{\prime \prime}$-Terpyridine
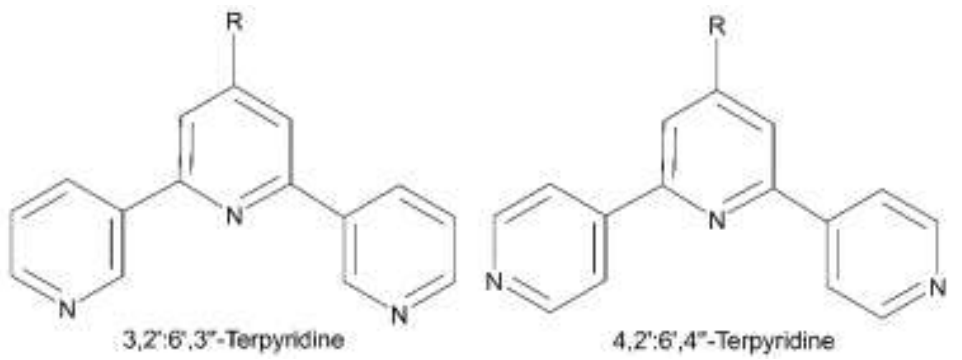

Scheme 1. 2,2,:6',2”, 3,2':6',3'” and 4,2':6',4”'-terpyridine molecules. 
The different spatial disposition of the nitrogen donors for these ligands gives a striking diversity of possible coordination modes, as easily revealed by looking at the CSD (v5.13 plus Feb. 2014 updates ${ }^{19}$ ). Table 1 presents a summary of the results obtained for these three types of Tpy-based compounds (Tpy = terpyridine), pointing out the number of reported moieties, either complexes or unbound and, among the former, the polymeric ones are prominent.

The most numerous, by far, is the $2,2^{\prime}: 6^{\prime}, 2^{\prime \prime}$ group that coordinates almost exclusively as $\mu_{1-\kappa^{3}}$ chelating ligands due to the convergent disposition of the $\mathrm{N}$ donors. The polymeric reported cases are the result of the bridging abilities of the eventual R substituent.

Table 1. Number of terpyridine based structures in the CSD database. ${ }^{19}$

\begin{tabular}{ccccc}
\hline Tpy Type & Uncomplexed & $\begin{array}{c}\text { Complexed } \\
\text { (Any metal) }\end{array}$ & $\begin{array}{c}\text { Complexed } \\
\text { (Polymeric) }\end{array}$ & $\begin{array}{c}\text { Polymeric } \\
\text { percentage }\end{array}$ \\
\hline $2,2^{\prime}: 6,2^{\prime \prime}-$ & 114 & 678 & 136 & $20 \%$ \\
$3,2^{\prime}: 6^{\prime}, 3^{\prime \prime}-$ & 2 & 11 & 8 & $73 \%$ \\
$4,2^{\prime}: 6^{\prime}, 4^{\prime \prime}-$ & 10 & 61 & 54 & $89 \%$ \\
\hline
\end{tabular}

On the other hand, the $3,2^{\prime}: 6^{\prime}, 3^{\prime \prime}$ group is the less frequently explored; the stereo-disposition of the outer pyridyl $\mathrm{N}$ donors makes possible various coordination modes, depending on the coordination habits of the metal. Thus, different coordination structures can be expected by using different metals centers, allowing both discrete as well as higher polymeric coordination arrangements. The 4,2':6',4" case ranks second in the number of entries, though far from the 2,2':6',2" case. All of these ligands are very versatile in their coordination modes: their different nature allows them connecting to metal centers acting either as bidentate-bridging (using the 4,4 "'pyridyl groups to give an infinite chain ${ }^{20-22}$ or a $3 \mathrm{D}$ network structure ${ }^{23}$ ) or as tridentate (using the three external 4-pyridyl groups which results in a 3D structural motif or molecular capsules ${ }^{11,24,25}$ ). This versatility makes this family of ligands very attractive in order to generate complex networks, as open 3D coordination structures (metal-organic framework, MOF's) which may lead to interesting physical properties such as luminescence ${ }^{26-29}$ or cooperative magnetism. . $^{130-32}$

Following our ideas of recent works using some 4,2':6',4"-terpyridine derivates: 4'-(3-methyl-2-thienyl)4,2':6',4"-terpyridine (4-stpy) and 4'-(4-quinolinyl)-4,2':6',4"-terpyridine, $\mathrm{C}_{25} \mathrm{H}_{17} \mathrm{Cl}_{3} \mathrm{~N}_{4}$, (4-qtpy) derivates meant to be used as complexing agents ${ }^{33}$, we are now interested in the copper(II) coordination chemistry based on 4'substituted- 4,2':6',4"- and 3,2':6',3'"-terpyridines (Scheme 2), among which 3-qtpy remains unexplored.

In this contribution, we report the successful attempts for the synthesis and structural exploration of four Copper(II) CPs, using these 4'-substituted-terpyridine ligands and bis( $\beta$-diketonate)metal(II) systems like 
Copper(II) hexafluoroacetylacetonate $\left[\mathrm{Cu}(\mathrm{hfacac})_{2}\right]$, the final products being formulated as: $\mathrm{Cu}(4-\mathrm{stpy})(\mathrm{hfacac})_{2}$ (I), $\mathrm{Cu}$ (4-qtpy)(hfacac) $)_{2}$ (II), $\mathrm{Cu}$ (3-qtpy)(hfacac) $)_{2}$ (III) and $\mathrm{Cu}$ (4-cntpy)(hfacac) $)_{2}$ (IV).

In addition to the structural studies, the synthesis, thermo-gravimetric, luminescent and magnetic properties are investigated and discussed. In sum, the objective of the present work is to observe how the molecular structure (distances and angles) influences the physical properties of these tpy-copper systems, on which there is scarce reported work in the literature.
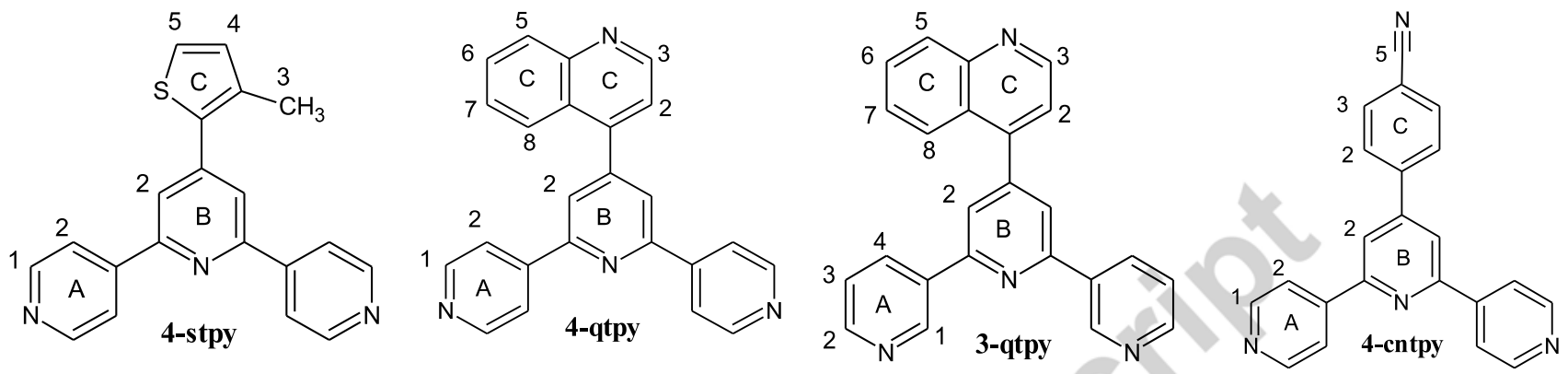

Scheme 2. 4,2':6',4''- and 3,2':6',3''-terpyridine ligands, presenting the atomic labelling for NMR spectroscopic assignments.

\section{Experimental}

2.1.- Syntheses of Ligands. All the ligands were prepared according to the aldol condensation and Michael addition methods ${ }^{34}$ with minor modifications; the chemical reagents were used without further purification. 4qtpy, 4-stpy and 4-cntpy were prepared as previously reported. ${ }^{33,35}$. 3-qtpy was prepared as follows:

\section{4'-(4-quinolinyl)-3,2':6',3'"-terpyridine.- (3-qtpy)}

3-acetylpyridine $(2.42 \mathrm{~g}, 20.0 \mathrm{mmol})$ was added to $20 \mathrm{~mL}$ of 4-quinolinylcarboxaldehyde ethanolic solution ( $1.56 \mathrm{~g}, 10 \mathrm{mmol})$. The solution was stirred by $10 \mathrm{~min}$, then $\mathrm{KOH}(1.12 \mathrm{~g}, 20 \mathrm{mmol})$ and $\mathrm{NH}_{4} \mathrm{OH}(29 \mathrm{~mL})$ were added. The mixture was stirred by $13 \mathrm{~h}$. A white powder was obtained and then filtered and washed with cold ethanol $(2 \times 15 \mathrm{~mL})$. Recrystallization of the ligand was done in $\mathrm{CHCl}_{3}(18 \mathrm{~mL})$. 3-qtpy was isolated as a white solid. $\mathrm{C}_{24} \mathrm{H}_{16} \mathrm{~N}_{4}(1525 \mathrm{mg}, 4,231 \mathrm{mmol}, 42.3 \%$ ). Anal, Calc: C, 79.98; H, 4.47; N, 15.54. Found: C, 79.28; H, 4.68; N, 15.61. ${ }^{1} \mathbf{H}$ NMR $\left(400 \mathrm{MHz}, \mathrm{CDCl}_{3}\right)\left(\mathrm{CDCl}_{3}\right) \delta 9.39\left(\mathrm{~d}, \mathrm{~J}=4.0 \mathrm{~Hz}, 2 \mathrm{H}, \mathrm{H}^{\mathrm{Al}}\right), 9.05(\mathrm{~d}, \mathrm{~J}=4.4 \mathrm{~Hz}, 1 \mathrm{H}$, $\left.\mathrm{H}^{\mathrm{C} 3}\right), 8.72\left(\mathrm{dd}, \mathrm{J}=4.8,1.7 \mathrm{~Hz}, 2 \mathrm{H}, \mathrm{H}^{\mathrm{A} 2}\right), 8.53\left(\mathrm{dt}, \mathrm{J}=8.0,2.0 \mathrm{~Hz}, 2 \mathrm{H}, \mathrm{H}^{\mathrm{A} 4}\right), 8.26\left(\mathrm{~d}, \mathrm{~J}=8.5 \mathrm{~Hz}, 1 \mathrm{H}, \mathrm{H}^{\mathrm{C} 5}\right), 7.90$ $\left(\mathrm{s}, 2 \mathrm{H}^{\mathrm{B} 2}\right), 7.88\left(\mathrm{~d}, \mathrm{~J}=4.0 \mathrm{~Hz}, 1 \mathrm{H}, \mathrm{H}^{\mathrm{C} 8}\right), 781\left(\mathrm{t}, \mathrm{J}=7.8 \mathrm{~Hz}, 1 \mathrm{H}, \mathrm{H}^{\mathrm{C} 6}\right), 7.59\left(\mathrm{t}, \mathrm{J}=7.8 \mathrm{~Hz}, 1 \mathrm{H}, \mathrm{H}^{\mathrm{C} 7}\right), 7.52-7.43$ $\left(\mathrm{m}, 3 \mathrm{H}, \mathrm{H}^{\mathrm{A} 3+\mathrm{C} 2}\right) \cdot{ }^{13} \mathrm{C}$ NMR $\left(101 \mathrm{MHz}, \mathrm{CDCl}_{3}\right)\left(\mathrm{CDCl}_{3}\right) \delta 155.38\left(\mathrm{C}^{\mathrm{B} 1}\right), 150.44\left(\mathrm{C}^{\mathrm{A} 2}\right), 149.95\left(\mathrm{C}^{\mathrm{C} 3}\right), 148.63$ $\left(\mathrm{C}^{\mathrm{A} 5}\right), 148.45\left(\mathrm{C}^{\mathrm{A} 1}\right), 148.37\left(\mathrm{C}^{\mathrm{C} 4}\right), 145.67\left(\mathrm{C}^{\mathrm{C} 9}\right), 134.91\left(\mathrm{C}^{\mathrm{A} 4}\right), 134.32\left(\mathrm{C}^{\mathrm{B} 3}\right), 130.31\left(\mathrm{C}^{\mathrm{C} 5}\right), 130.20\left(\mathrm{C}^{\mathrm{C} 6}\right), 127.82$ $\left(\mathrm{C}^{\mathrm{C} 7}\right), 125.92\left(\mathrm{C}^{\mathrm{C} 1}\right), 125.00\left(\mathrm{C}^{\mathrm{C} 8}\right), 122.95\left(\mathrm{C}^{\mathrm{A} 3}\right), 121.05\left(\mathrm{C}^{\mathrm{B} 2}\right), 120.14\left(\mathrm{C}^{\mathrm{C} 2}\right)$. FT-IR $\left(\mathrm{KBr}, \mathrm{cm}^{-1}\right) 3043($ merged 
$\nu_{\mathrm{CH}}$ pyridine and quinolone rings), 1591, 1545, 1510 and 1387 ( $\nu_{\mathrm{CC}}$ pyridine and quinoline rings), 1198(m), $1128(\mathrm{w}), 1024(\mathrm{~m}), 864(\mathrm{~m}), 816(\mathrm{~s}), 762(\mathrm{~s}), 702(\mathrm{~s}), 615(\mathrm{~m})$.

\section{2.- Syntheses of Complexes.}

For all reactions, the amounts involved are in agreement with stoichiometry criteria, that is, necessity to have ca. 1: 1 or 1: 2 ratios between ligand (tpy) and metal ion; however, sometimes empirical experience indicates that we must use excess of ligand, as in the first reaction below.

\section{Cu(4-stpy)(hfacac) 2}

A solution $\mathrm{Cu}(\mathrm{hfacac})_{2} \cdot \mathrm{H}_{2} \mathrm{O}(80 \mathrm{mg}, 0.167 \mathrm{mmol})$ in $\mathrm{EtOH}(10 \mathrm{~mL})$ was placed in a test tube. Then EtOH $(3.0$ $\mathrm{mL}$ ) was poured on the top of the solution, followed by a solution of 4-stpy ( $80 \mathrm{mg}, 0.243 \mathrm{mmol}) \mathrm{in}$ EtOH (15 $\mathrm{mL}$ ). The test tube was sealed with parafilm standing for 5 days at room temperature. Green needles quickly resulted which were filtered. The crystals were washed with $\mathrm{EtOH}$, and dried in air $\mathrm{C}_{30} \mathrm{H}_{17} \mathrm{CuF}_{12} \mathrm{~N}_{3} \mathrm{O}_{4} \mathrm{~S}$ (86 mg, 0.106 mmol, 65,43 \%). Anal, Calc: C, 44.65; H, 2.12; N, 5.21; S: 3.97. Found: C: 44.89; 2.82; N, 5.77; S: 3.76. FT-IR (solid, $\mathrm{cm}^{-1}$ ): $3118(\mathrm{w}), 3077$ (vw, $\left.v_{\mathrm{C}-\mathrm{H}} \operatorname{arom}\right) ; 2931(\mathrm{vw}), 2867(\mathrm{vw}), 1656\left(\mathrm{~s}, v_{\mathrm{C}=0}\right) ; 1606(\mathrm{~s}) 1535(\mathrm{~s})$ $1490(\mathrm{~s})$ and $1415(\mathrm{~m})\left(v_{\mathrm{CC}}\right.$ and $\left.v_{\mathrm{CN}}\right) ; 1328,(\mathrm{w}), 1259(\mathrm{vs}), 1203(\mathrm{vs}), 1143(\mathrm{vs}), 836(\mathrm{~m}), 727(\mathrm{~m}), 665\left(\mathrm{~m}, v_{\mathrm{Cu}-}\right.$ o), $586(w)$.

\section{II. $\left(\mathrm{Cu}(4-q t p y)(\text { hfacac })_{2}\right.$}

A solution $\mathrm{Cu}(\mathrm{hfacac})_{2} \cdot \mathrm{H}_{2} \mathrm{O}(95.2 \mathrm{mg}, 0.199 \mathrm{mmol})$ in $\mathrm{CHCl}_{3}(10 \mathrm{~mL})$ was added to a solution of 4-qtpy (95.6 $\mathrm{mg}, 0.199 \mathrm{mmol})$ in $\mathrm{CHCl}_{3}(15 \mathrm{~mL})$ and the reaction mixture was stirred at room temperature for $15 \mathrm{~min}$. The solution was left to stand at room temperature; green blocks suitable for single crystal X-ray analysis were recovered after 2 days. $\mathrm{C}_{34} \mathrm{H}_{18} \mathrm{Cu} \mathrm{F}_{12} \mathrm{~N}_{4} \mathrm{O}_{4}, \mathrm{C} \mathrm{H} \mathrm{Cl}_{3}(135 \mathrm{mg}, 0.141 \mathrm{mmol}, 70.85 \%$ ) Anal, Calc: C, 43.91; $\mathrm{H}$, 2.00; N, 5.85 Found: C: 44.27.; H, 1.96; N, 6.18. After evaporation of the solvent, the sample rapidly becomes opaque. FT-IR (solid, $\mathrm{cm}^{-1}$ ): 3070 (vw, $v_{\mathrm{C}-\mathrm{H}}$ arom); 1658 (vs, $v_{\mathrm{C}=\mathrm{O}}$ ); 1614 (m) 1533 (s) 1516 (s) and $1402(\mathrm{~m})$ $\left(v_{\mathrm{CC}}\right.$ and $\left.v_{\mathrm{CN}}\right) ; 1326(\mathrm{w}), 1257(\mathrm{vs}), 1198(\mathrm{vs}), 1144(\mathrm{vs}), 1078(\mathrm{~m}), 991(\mathrm{vw}), 879(\mathrm{vw}), 843(\mathrm{~m}), 795(\mathrm{w}), 756$ (m), $661\left(\mathrm{~m}, v_{\mathrm{Cu}-\mathrm{O}}\right), 621(\mathrm{w}), 584(\mathrm{w})$.

\section{III. $\mathrm{Cu}(3-q t p y)(h f a c a c)_{2}$}

A solution $\mathrm{Cu}(\mathrm{hfacac})_{2} \cdot \mathrm{H}_{2} \mathrm{O}(92.5 \mathrm{mg}, 0.194 \mathrm{mmol})$ in $\mathrm{CHCl}_{3}(10 \mathrm{~mL})$ was added to a solution of 3-qtpy (69.8 $\mathrm{mg}, 0.194 \mathrm{mmol})$ in $\mathrm{CHCl}_{3}(15 \mathrm{~mL})$ and the reaction mixture was stirred at room temperature for $15 \mathrm{~min}$. After slow evaporation of the solvent at room temperature single crystals were obtained after 3 days. $\mathrm{C}_{34} \mathrm{H}_{18} \mathrm{CuF}_{12} \mathrm{~N}_{4} \mathrm{O}_{4} \cdot \mathrm{CHCl}_{3}(154 \mathrm{mg}, 0.160 \mathrm{mmol}, 82.47$ \%). Anal, Calc: C, 43.91; H, 2.00; N, 5.85 Found: C: 43.42.; H, 2.21; N, 5.60. FT-IR (solid, $\mathrm{cm}^{-1}$ ): 3081 (vw, $v_{\mathrm{C}-\mathrm{H}}$ arom); 1662 (vs, $v_{\mathrm{C}=\mathrm{O}}$ ); 1612 (m) 1537 (s) 1506 (s) 
and $1419(\mathrm{~m})\left(v_{\mathrm{CC}}\right.$ and $\left.v_{\mathrm{CN}}\right) ; 1396(\mathrm{~m}), 1334(\mathrm{~m}), 1259(\mathrm{vs}), 1205(\mathrm{vs}), 1140(\mathrm{vs}), 1089(\mathrm{~s}), 939(\mathrm{w}), 897(\mathrm{w})$, $856(\mathrm{w}), 802(\mathrm{~m}), 758(\mathrm{~s}), 700(\mathrm{~m}), 665\left(\mathrm{~m}, v_{\mathrm{Cu}-\mathrm{O}}\right), 621(\mathrm{w}), 582(\mathrm{~m})$.

\section{Cu(4-cntpy)(hfacac) ${ }_{2}$}

A solution $\mathrm{Cu}(\mathrm{hfacac})_{2} \cdot \mathrm{H}_{2} \mathrm{O}(43.94 \mathrm{mg}, 0.092 \mathrm{mmol})$ in $\mathrm{CHCl}_{3}(10 \mathrm{~mL})$ was added to a solution of 4-cntpy (61.7 mg, $0.184 \mathrm{mmol})$ in $\mathrm{CHCl}_{3}: \mathrm{MeOH}(20 \mathrm{~mL}, \mathrm{v} / \mathrm{v}, 3: 1)$ and the reaction mixture was stirred at room temperature for $15 \mathrm{~min}$. The solution was left to stand at room temperature for 3 days and dark green blocks suitable for single crystal X-ray analysis were obtained.After filtration, the crystals were washed with ethanol, and dried in air $\mathrm{C}_{64} \mathrm{H}_{32} \mathrm{Cu}_{2} \mathrm{~F}_{24} \mathrm{~N}_{8} \mathrm{O}_{8}(75 \mathrm{mg}, 0.0462 \mathrm{mmol}, 50.2 \%$ ). Anal, Calc: $\mathrm{C}, 47.33 ; \mathrm{H}, 1.99 ; \mathrm{N}, 6.90$. Found: C: 47.91; H, 2.07; N, 7.04. FT-IR (solid, $\mathrm{cm}^{-1}$ ): 3126(w), 3081 (vw, $\left.v_{\mathrm{C}-\mathrm{H}} \operatorname{arom}\right) ; 2927(\mathrm{vw}), 2952(\mathrm{vw})$, 2227(w, $\left.v_{\mathrm{CN}}\right)$ 1654(s, $\left.v_{\mathrm{C}=0}\right) ; 1608(\mathrm{~s}) 1537(\mathrm{~s}) 1490(\mathrm{~s})$ and $1402(\mathrm{~s})$ ( $v_{\mathrm{CC}}$ and $\left.v_{\mathrm{CN}}\right) ; 1328,(\mathrm{w}), 1257$ (vs), 1211(vs), 1143 (vs), $836(\mathrm{~m}), 800(\mathrm{~m}), 759(\mathrm{~m}), 665$ (m, $\left.v_{\mathrm{Cu}-\mathrm{O}}\right), 584(\mathrm{~m})$.

NMR spectroscopy. ${ }^{1} \mathrm{H}$ and ${ }^{13} \mathrm{C}$ NMR spectra in $\mathrm{CDCl}_{3}$ solution were recorded on a Bruker-400 NMR spectrometer (chemical shifts referenced to residual solvent peaks, $\delta_{\mathrm{TMS}}=0$ ).

Infrared spectra. Infrared spectra were obtained from $\mathrm{KBr}$ pellets on a Bruker EQUINOX 55 Fourier transform infrared spectrometer in the $400-4000 \mathrm{~cm}^{-1}$ region.

\subsection{Spectroscopic and photophysical measurements.}

Steady state absorption. UV-Vis absorption spectra of compounds I-IV in aerated solvent solutions were recorded on an Agilent 8453 Diode-Array spectrophotometer in the range of 250-800 nm. Molar absorption was determined according to Lambert-Beer Law by measuring absorbance at $\lambda=265 \mathrm{~nm}$ and $\lambda=310 \mathrm{~nm}$ for concentrations of solutions ranging from $1 \mu \mathrm{M}<\mathrm{c}<20 \mu \mathrm{M}$.

Steady state emission. Emission spectra of compounds I-IV in air-saturated $\mathrm{CH}_{2} \mathrm{Cl}_{2}$ solvent solutions were measured in a Horiba Jobin-Yvon FluoroMax-4 spectrofluorometer at room temperature. Quantum yields of luminescence were measured at room temperature using quinine sulfate in $0.1 \mathrm{M} \mathrm{H}_{2} \mathrm{SO}_{4}$ (quantum yield $\left(\Phi_{\mathrm{em}}\right)=$ 0.546 for excitation at $\lambda=350 \mathrm{~nm})^{36}$ as actinometer. Emission spectra for samples in the solid state were measured at an angle $\theta=45^{\circ}$.

The optical densities of the sample $\left(O D_{x}\right)$ and actinometer $\left(O D_{s t d}\right)$ solutions were set below 0.10 and matched at the excitation wavelength. The emission quantum yield of the sample $\left(\emptyset_{x}\right)$ was calculated by using Eq. 1:

$$
\emptyset_{x}=\emptyset_{s t d} \frac{I_{x}}{I_{s t d}}\left(\frac{O D_{s t d}}{O D_{x}}\right)\left(\frac{\eta_{x}}{\eta_{s t d}}\right)^{2} \text { (Eq. 1) }
$$


where $\emptyset_{s t d}$ is the known quantum yield of the actinometer, $\mathrm{I}_{\mathrm{x}}$ and $\mathrm{I}_{\text {std }}$ are the integrated fluorescence intensities for the sample and actinometer respectively, and $\eta_{\mathrm{x}}$ and $\eta_{\text {std }}$ are the refractive index of sample and actinometer solutions respectively.

Time resolved emission. Luminescence decay curves were recorded using the time-correlated single photon counting technique in a PicoQuant FluoTime 300 fluorescence lifetime spectrometer. A sub-nanosecond Pulsed LED PLS-305 was employed as the pulsed light source (FWHM 500 ps; average power $10 \mathrm{MHz}$ ).

Computational Calculations. All geometry optimizations were performed at the RB3LYP/6-31+G(d,p) level of theory using the Gaussian09 Rev C.01 package of programs (G09). ${ }^{37}$ The frontier molecular orbitals were calculated for each compound. In this work, all calculations were performed in vacuum, starting with the geometry determined from X-ray diffraction.

Thermogravimetric analysis. Thermogravimetric analysis (TGA) were carried out with a Universal V2.6 DTA system at a rate of $10^{\circ} \mathrm{C} / \mathrm{min}$ in a nitrogen atmosphere.

$X$-ray powder diffraction was measured by using a Bruker D8 Advance diffractometer at $40 \mathrm{kV}, 40 \mathrm{~mA}$ with a $\mathrm{Cu}$-target tube and a graphite monochromator.

Magnetic measurements. The magnetic susceptibility was measured between $2 \mathrm{~K}$ and $300 \mathrm{~K}$, using a SQUID magnetometer (MPMS-XL) at an applied field of 500 Oe (0.05 Tesla). Powder samples were placed inside a gelatin capsule. The diamagnetic contribution was obtained from experimental data through $\chi_{\mathrm{M}} \cdot \mathrm{T}$ vs $\mathrm{T}$ plots and then, subtracted. The temperature independent magnetic contribution due to the sample holder was subtracted at all temperatures.

\section{Refinement}

Diffraction patterns were recorded using two different Bruker SMART AXS CCD diffractometers with graphite-monochromated $\mathrm{Mo} \mathrm{K}_{\alpha}$ radiation $(\lambda=0.71073 \AA)$, those for $\mathbf{I}$ and $\mathbf{I I}$ at room temperature, while those for III and IV at 150K; semi-empirical absorption corrections based on symmetry equivalent reflections were applied.

Structures I and II were solved by direct methods with SHELXS ${ }^{38}$ and refined by full-matrix least-squares based on $\mathrm{F}^{2}$ using SHELXL-2014 ${ }^{39}$. Structure analysis was performed with the aid of Platon ${ }^{40}$. In both structures (I, II) the trifluoro-methane groups appeared rotationally disordered; for this reason data was split into two $\mathrm{F}_{3}$ sets attached to each methyl carbon, subjected to strict metric restraints and with complementary occupation factors, spanning the range 0.660 (7)-0.894 (5) for I and 0.51 (3)-0.66 (2) for II for the major fractions. In the case of $\mathbf{I}$, the minor $\mathrm{F}_{3}$ fraction was refined with a single, isotropic displacement factor because 
of the low occupation.

On other hand, structures III and IV, were solved by direct methods using $S I R 97^{41}$, then refined with fullmatrix least-squares methods based on $F^{2}$ (SHELXL-97) ${ }^{38}$ with the aid of the WINGX ${ }^{42}$ program.

All non-hydrogen atoms were refined with anisotropic atomic displacement parameters. $\mathrm{H}$ atoms were finally included in their calculated positions and treated as riding, with $\mathrm{d}(\mathrm{C}-\mathrm{H})=0.93 \AA$ for $\mathrm{CH}$ and $0.96 \AA$ for $\mathrm{CH}_{3}$. They were assigned isotropic displacement factors 1.2/1.5 times the equivalent factor for the host carbon.

For structures II and IV the contribution of the undetected disordered solvents to the calculated structure factors was estimated following the BYPASS algorithm ${ }^{43}$ implemented as the SQUEEZE option in PLATON ${ }^{40}$. A new set of data, free of solvent contribution has been then used in the final refinement.

Publication material was generated using PublCif ${ }^{44}$ and XP in the SHELXTL crystallographic package. ${ }^{38}$

Details about crystal data, data collection and refinement parameters are documented in Table 2.

Table 2 Crystal data, data collection and refinement details for compounds I-IV.

\begin{tabular}{|c|c|c|c|c|}
\hline & I & II & III & IV \\
\hline Chemical formula & $\mathrm{C}_{30} \mathrm{H}_{17} \mathrm{CuF}_{12} \mathrm{~N}_{3} \mathrm{O}_{4} \mathrm{~S}$ & $\mathrm{C}_{34} \mathrm{H}_{18} \mathrm{CuF}_{12} \mathrm{~N}_{4} \mathrm{O}_{4} \cdot \mathrm{CHCl}_{3}$ & $\mathrm{C}_{34} \mathrm{H}_{18} \mathrm{CuF}_{12} \mathrm{~N}_{4} \mathrm{O}_{4} \cdot \mathrm{CHCl}_{3}$ & $\mathrm{C}_{64} \mathrm{H}_{32} \mathrm{Cu}_{2} \mathrm{~F}_{24} \mathrm{~N}_{8} \mathrm{O}_{8}$ \\
\hline $\mathrm{M}_{\mathrm{r}}$ & 807.07 & 957.43 & 957.43 & 1624.06 \\
\hline $\begin{array}{l}\text { Crystal system, } \\
\text { Space group }\end{array}$ & $\begin{array}{l}\text { Monoclinic } \\
\qquad P 2_{1} / n\end{array}$ & $\begin{array}{c}\text { Monoclinic } \\
P 2_{1} / c\end{array}$ & $\begin{array}{l}\text { Orthorhombic } \\
\qquad P b c a\end{array}$ & $\begin{array}{c}\text { Monoclinic } \\
\mathrm{C} 2 / c\end{array}$ \\
\hline $\mathrm{a},(\AA)$ & $12.243(2)$ & $11.286(2)$ & $15.2176(5)$ & $21.422(11)$ \\
\hline $\mathrm{b},(\AA)$ & $15.603(3)$ & $24.821(5)$ & $18.6531(5)$ & $13.980(8)$ \\
\hline $\mathrm{c},(\AA)$ & $16.475(3)$ & $15.438(3)$ & $26.4674(7)$ & $25.039(13)$ \\
\hline$\beta\left(^{\circ}\right)$ & $90.73(3)$ & $108.610(3)$ & & $115.666(2)$ \\
\hline $\mathrm{V}\left(\AA^{3}\right)$ & $3146.8(11)$ & 4098.4(14) & $7512.9(4)$ & $6758.9(6)$ \\
\hline $\mathrm{Z}$ & 4 & 4 & 8 & 4 \\
\hline$\mu\left(\mathrm{mm}^{-1}\right)$ & 0.87 & 0.83 & 0.900 & 0.76 \\
\hline$R_{\text {int }} \bigcirc$ & 0.118 & 0.092 & 0.0382 & 0.0498 \\
\hline $\begin{array}{c}\text { Measured } \\
\text { Independent } \\
\text { Observed reflections } \\
{[\mathrm{I}>2 \sigma(\mathrm{I})]}\end{array}$ & $\begin{array}{c}65910 \\
8884 \\
4563\end{array}$ & $\begin{array}{c}138929 \\
7423 \\
5313\end{array}$ & $\begin{array}{c}111616 \\
8613 \\
6800\end{array}$ & $\begin{array}{c}21905 \\
7675 \\
4120\end{array}$ \\
\hline $\mathrm{R}\left[\mathrm{F}^{2}>2 \sigma\left(\mathrm{F}^{2}\right)\right], w \mathrm{R}\left(\mathrm{F}^{2}\right), S$ & $0.077,0.252,1.05$ & $0.069,0.189,1.14$ & $0.061,0.156,1.03$ & $0.064,0.176,0.992$ \\
\hline $\begin{array}{l}\text { No. of reflections, } \\
\text { parameters, restraints }\end{array}$ & $8884,505,544$ & $7423,649,504$ & $8613,532,0$ & $7675,469,0$ \\
\hline$\Delta_{\max }, \Delta_{\min }\left(\varepsilon . \AA^{-3}\right)$ & $1.05,-0.84$ & $1.00,-0.54$ & $1.761,-1.537$ & $0.997,-0.52$ \\
\hline
\end{tabular}

\section{RESULTS AND DISCUSSION}

\subsection{Synthesis of Ligands and characterization}


Ligand 3-qtpy was prepared using a one pot method, treating 4-quinolinecarboxaldehyde with 3-acetylpyridine in basic EtOH, followed by addition of aqueous $\mathrm{NH}_{3}$.

We have assigned the ${ }^{1}$ H NMR (Fig. S1) and ${ }^{13}$ C NMR (Fig. S2) spectroscopic data of 3qtpy using routine 2D methods and found them in agreement with the proposed structure. In the ${ }^{1} \mathrm{H}-\mathrm{NMR}$ spectra of 3-qtpy, the position of N-donor atoms gives rise to corresponding ${ }^{1} \mathrm{H}$-splitting pattern of the 3,2'-6',3"-terpyridine domain (AB-Pattern for protons $\mathrm{H}^{\mathrm{A} 1}, \mathrm{H}^{\mathrm{A} 2}$, $\mathrm{H}^{\mathrm{A} 4}, \mathrm{H}^{\mathrm{B} 2}$ and $\mathrm{H}^{\mathrm{A} 3}$, with chemical shifts at $\delta=9.39,8.72,8.53,7.92$ and $7.49 \mathrm{ppm}$, respectively). An overlap of signals occurs for the $\mathrm{H}^{\mathrm{A} 3}$ and $\mathrm{H}^{\mathrm{C} 2}$ protons (multiplet at 7.52$7.43 \mathrm{ppm}$ ), but all quinoline protons can be readily distinguished using COSY and HSQC experiments. Similarly, the ${ }^{13} \mathrm{C}$ NMR spectrum shows the corresponding signals of the fragment $3,2^{\prime}-6^{\prime}, 3^{\prime \prime}$-terpyridine in the aromatic area: three lines are attributed to quaternary carbons at approximately $155.38\left(\mathrm{C}^{\mathrm{B} 1}\right), 148.6\left(\mathrm{C}^{\mathrm{A} 5}\right)$ and $134.32\left(\mathrm{C}^{\mathrm{B} 3}\right)$ ppm and five lines due to $\mathrm{CH}$ carbons at approximately $150.44\left(\mathrm{C}^{\mathrm{A} 2}\right), 148.50\left(\mathrm{C}^{\mathrm{A} 1}\right), 134.9\left(\mathrm{C}^{\mathrm{A} 4}\right), 122.95\left(\mathrm{C}^{\mathrm{A} 3}\right)$ and $121.05\left(\mathrm{C}^{\mathrm{B} 2}\right) \mathrm{ppm}$. Signals due to $\mathrm{CH}$ carbons of the substituent quinoline ring are observed at $149.95\left(\mathrm{C}^{\mathrm{C} 3}\right), 130.31\left(\mathrm{C}^{\mathrm{C} 5}\right), 130.20\left(\mathrm{C}^{\mathrm{C} 6}\right), 127.82\left(\mathrm{C}^{\mathrm{C} 7}\right), 125.00\left(\mathrm{C}^{\mathrm{C} 8}\right)$, and $120.14\left(\mathrm{C}^{\mathrm{C} 2}\right) \mathrm{ppm}$.

3-qtpy is highly soluble in solvents as $\mathrm{CHCl}_{3}, \mathrm{CH}_{2} \mathrm{Cl}_{2}, \mathrm{DMF}$, DMSO and slightly soluble in $\mathrm{MeOH}$ and $\mathrm{EtOH}$.

\subsection{Characterization and Structural Description of Copper(II) Coordination Polymers.}

Compounds I-IV were separated as air-stable crystalline solids and were characterized by elemental analysis, spectrometric (IR and UV-Vis), TGA, luminescent and magnetic measurements.

These compounds have characteristic fundamental vibration modes and, in most cases, the corresponding bands can be identified in a relatively easy way. FT-IR spectra for compounds I-IV are shown in Fig. S3. The observed bands at $3200-3000 \mathrm{~cm}^{-1}$ were attributed to unsaturated $v \mathrm{CH}$ stretching vibration modes of the aromatic rings. Besides, for compound I, two weak bands at 2931 and $2867 \mathrm{~cm}^{-1}$ were observed due to the $v \mathrm{CH}$ stretching vibration of the aliphatic moiety $\left(-\mathrm{CH}_{3}\right)$.

For compound IV, a band around $2227 \mathrm{~cm}^{-1}$ was observed due to the $\nu \mathrm{CN}$ stretching vibration of the nitrile moiety $(-\mathrm{C} \equiv \mathrm{N})$. 
Additionally, all spectra exhibit a series of bands between $1600-1300 \mathrm{~cm}^{-1}$ indicating the presence of the $v(\mathrm{C} \cdots \mathrm{O}), v(\mathrm{C} \cdots \mathrm{C})$ and $v(\mathrm{C} \cdots \mathrm{N})$ bonds. ${ }^{45}$ Besides, a series of three strong bands in the $1300-1100 \mathrm{~cm}^{-1}$ region were assigned to the stretching vibration modes of the $\mathrm{C}-\mathrm{F}$ bonds in the $-\mathrm{CF}_{3}$ groups. ${ }^{46,47}$

The thienyl moiety in compound I was confirmed due to the presence of strong bands at $727 \mathrm{~cm}^{-1}$ and attributed to the out of plane bending vibration mode of the $\mathrm{C}-\mathrm{H}$ groups present in 4-stpy ligand. $^{48,49}$

This information is consistent with the crystal structure determined by X-ray diffraction (see below).

Fig. 1 shows the structural diagrams of compounds I and II, while Fig. 2 presents those for III and IV. The general formulation of the non-solvent part of the structures is similar in all cases, corresponding to one $\mathrm{Cu}(\mathrm{hfacac})_{2}$ unit bound to the corresponding terpyridyl ligand. There is just one of these formulas in each asymmetric unit $\left(z^{\prime}=1\right)$; however, while this is achieved with one single copper cation in compounds I, II and III, in compound IV there are two independent copper atoms in the asymmetric unit, laying on inversion centres. The four coordination polyhedra are rather similar, having two hfacac units chelating the copper cations while the nitrogenated bases act as $\mu_{2}$ bidentate bridging linkers of the metal centers to form undulating chains of different shapes. The way in which these terpyridine linkers bind the cation differs, being cis in I, III and trans in II and IV. Fig. 3 shows a sketch of all the coordination polyhedra, while the coordination parameters are given in Table 3 for compounds I, II, III and Table 4 for compound IV. 

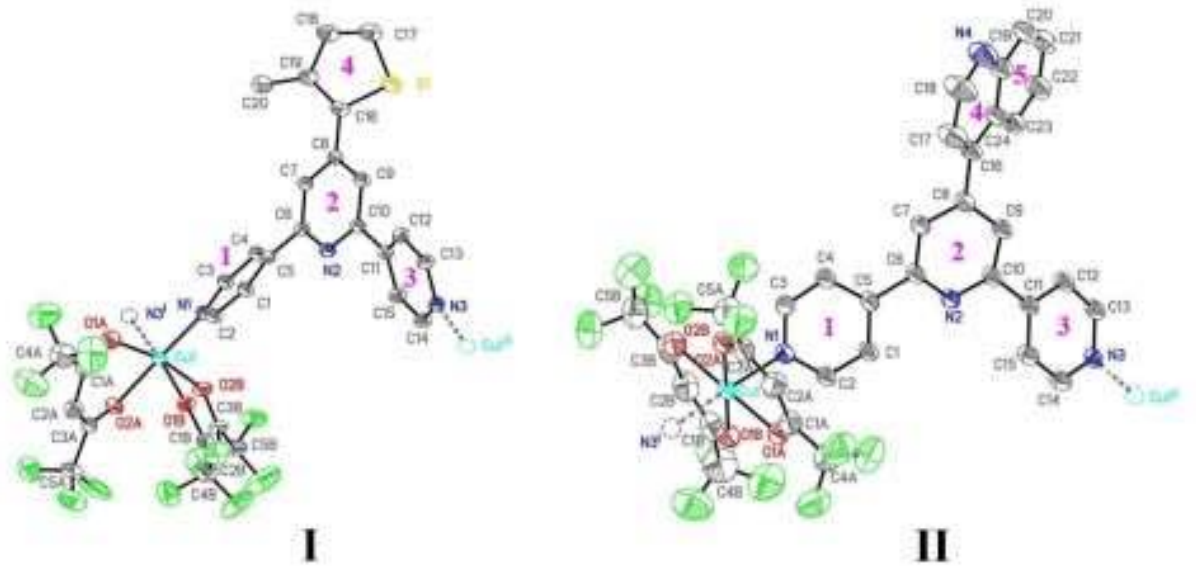

Fig. 1: Displacement ellipsoid plots (35\% probability level) for I and II. Symmetry codes for structure I: (i) $x-1, y, z$ and structure II: (i) $-x, y-1 / 2,-z+1 / 2$.
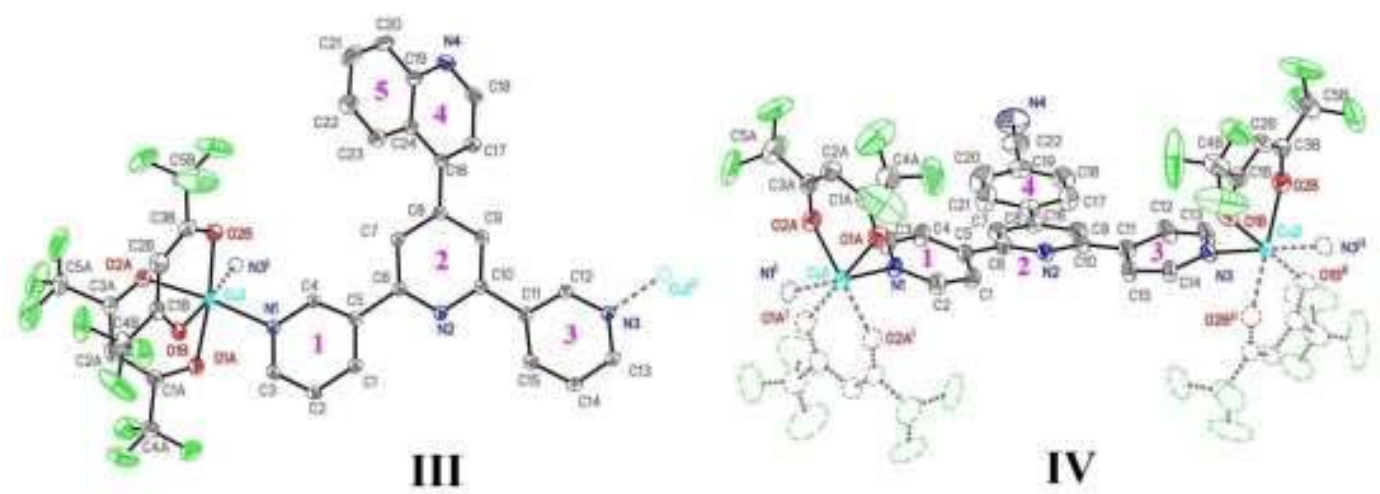

Fig. 2: Structures of III and IV with ellipsoids plotted at the 50\% probability level. Symmetry codes: For III:(i) 1/2+x,1/2-y,-z ; For IV: (i) -x,2-y,1-z; (ii)1-x,2-y,2-z. 
Table 3.

Selected bond distances $(\AA)$ and angles $\left(^{\circ}\right)$ for compounds I, II and III

\begin{tabular}{|c|c|c|c|}
\hline & I & II & III \\
\hline \multicolumn{4}{|l|}{ Bond distances } \\
\hline $\mathrm{Cu} 1-\mathrm{O} 1 \mathrm{~B}$ & $1.993(3)$ & $2.043(4)$ & $1.964(2)$ \\
\hline $\mathrm{Cu} 1-\mathrm{O} 2 \mathrm{~A}$ & $2.009(3)$ & $2.057(3)$ & $2.009(2)$ \\
\hline $\mathrm{Cu} 1-\mathrm{N} 3^{\mathrm{i}}$ & $2.011(3)$ & $2.017(4)$ & $1.996(3)$ \\
\hline $\mathrm{Cu} 1-\mathrm{N} 1$ & $2.019(3)$ & $2.010(4)$ & $2.040(3)$ \\
\hline $\mathrm{Cu} 1-\mathrm{O} 2 \mathrm{~B}$ & $2.259(3)$ & $2.203(4)$ & $2.244(2)$ \\
\hline $\mathrm{Cu} 1-\mathrm{O} 1 \mathrm{~A}$ & $2.277(4)$ & $2.211(4)$ & $2.275(2)$ \\
\hline \multicolumn{4}{|l|}{ Angles } \\
\hline $\mathrm{O} 2 \mathrm{~A}-\mathrm{Cu} 1-\mathrm{N} 3^{\mathrm{i}}$ & $89.89(14)$ & $89.04(14)$ & $89.14(10)$ \\
\hline $\mathrm{O} 1 \mathrm{~B}-\mathrm{Cu} 1-\mathrm{N} 1$ & $88.96(13)$ & $90.62(14)$ & $88.88(10)$ \\
\hline $\mathrm{O} 1 \mathrm{~B}-\mathrm{Cu} 1-\mathrm{O} 2 \mathrm{~B}$ & $85.78(13)$ & $87.60(16)$ & $88.35(10)$ \\
\hline $\mathrm{O} 2 \mathrm{~A}-\mathrm{Cu} 1-\mathrm{O} 2 \mathrm{~B}$ & $86.11(14)$ & $91.44(15)$ & $87.99(9)$ \\
\hline $\mathrm{N} 3^{\mathrm{i}}-\mathrm{Cu} 1-\mathrm{O} 2 \mathrm{~B}$ & $92.88(13)$ & $91.13(15)$ & $91.83(10)$ \\
\hline $\mathrm{N} 1-\mathrm{Cu} 1-\mathrm{O} 2 \mathrm{~B}$ & $99.00(14)$ & $93.10(16)$ & $96.08(10)$ \\
\hline $\mathrm{O} 1 \mathrm{~B}-\mathrm{Cu} 1-\mathrm{O} 1 \mathrm{~A}$ & $88.71(14)$ & $94.27(16)$ & $88.39(10)$ \\
\hline $\mathrm{O} 2 \mathrm{~A}-\mathrm{Cu} 1-\mathrm{O} 1 \mathrm{~A}$ & $84.58(14)$ & $86.69(15)$ & $86.65(9)$ \\
\hline $\mathrm{N} 3^{\mathrm{i}}-\mathrm{Cu} 1-\mathrm{O} 1 \mathrm{~A}$ & $91.81(15)$ & $88.98(15)$ & $91.02(10)$ \\
\hline $\mathrm{N} 1-\mathrm{Cu} 1-\mathrm{O} 1 \mathrm{~A}$ & $89.74(14)$ & $86.76(15)$ & $89.02(9)$ \\
\hline $\mathrm{O} 2 \mathrm{~B}-\mathrm{Cu} 1-\mathrm{O} 1 \mathrm{~A}$ & $169.57(13)$ & $178.13(14)$ & $173.89(9)$ \\
\hline $\mathrm{O} 1 \mathrm{~B}-\mathrm{Cu} 1-\mathrm{N} 3^{\mathrm{i}}$ & $174.78(13)$ & $90.58(14)$ & $175.51(11)$ \\
\hline $\mathrm{O} 2 \mathrm{~A}-\mathrm{Cu} 1-\mathrm{N} 1$ & $171.79(13)$ & $89.83(14)$ & $173.67(10)$ \\
\hline $\mathrm{O} 1 \mathrm{~B}-\mathrm{Cu} 1-\mathrm{O} 2 \mathrm{~A}$ & $84.99(15)$ & $178.96(17)$ & $86.39(10)$ \\
\hline $\mathrm{N} 3{ }^{\mathrm{i}}-\mathrm{Cu} 1-\mathrm{N} 1$ & $96.23(13)$ & $175.64(17)$ & $95.56(11)$ \\
\hline
\end{tabular}




\section{Table 4.}

Selected bond distances $(\AA)$ and angles $\left(^{\circ}\right)$ for compound IV

\begin{tabular}{|c|c|c|c|}
\hline \multicolumn{4}{|l|}{ Bond distances } \\
\hline $\mathrm{Cu} 1-\mathrm{O} 1 \mathrm{~A}$ & $2.268(3)$ & $\mathrm{Cu} 2-\mathrm{O} 1 \mathrm{~B}$ & $2.129(3)$ \\
\hline $\mathrm{Cu} 1-\mathrm{O} 2 \mathrm{~A}$ & $2.011(3)$ & $\mathrm{Cu} 2-\mathrm{O} 2 \mathrm{~B}$ & $2.135(3)$ \\
\hline $\mathrm{Cu} 1-\mathrm{N} 1$ & $2.034(3)$ & $\mathrm{Cu} 2-\mathrm{N} 3$ & $2.010(3)$ \\
\hline \multicolumn{4}{|l|}{ Angles } \\
\hline $\mathrm{O} 1 \mathrm{~A}-\mathrm{Cu} 1-\mathrm{O} 1 \mathrm{~A}$ & 180.00 & $\mathrm{O} 1 \mathrm{~B}-\mathrm{Cu} 2-\mathrm{O} 1 \mathrm{~B}^{\mathrm{ii}}$ & 180.00 \\
\hline $\mathrm{O} 2 \mathrm{~A}-\mathrm{Cu} 1-\mathrm{O} 1 \mathrm{~A}$ & $86.37(11)$ & $\mathrm{O} 1 \mathrm{~B}-\mathrm{Cu} 2-\mathrm{O} 2 \mathrm{~B}^{\mathrm{ii}}$ & $92.28(10)$ \\
\hline $\mathrm{O} 2 \mathrm{~A}^{\mathrm{i}}-\mathrm{Cu} 1-\mathrm{O} 1 \mathrm{~A}^{\mathrm{i}}$ & $86.36(11)$ & $\mathrm{O}_{1} \mathrm{~B}^{\mathrm{ii}}-\mathrm{Cu} 2-\mathrm{O} 2 \mathrm{~B}$ & $92.29(10)$ \\
\hline $\mathrm{O} 2 \mathrm{~A}^{\mathrm{i}}-\mathrm{Cu} 1-\mathrm{O} 1 \mathrm{~A}$ & $93.63(11)$ & $\mathrm{O} 1 \mathrm{~B}^{\mathrm{ii}}-\mathrm{Cu} 2-\mathrm{O} 2 \mathrm{~B}^{\mathrm{ii}}$ & $87.72(10)$ \\
\hline $\mathrm{O} 2 \mathrm{~A}-\mathrm{Cu} 1-\mathrm{O} \mathrm{A}^{\mathrm{i}}$ & $93.63(11)$ & $\mathrm{O} 1 \mathrm{~B}-\mathrm{Cu} 2-\mathrm{O} 2 \mathrm{~B}$ & $87.71(10)$ \\
\hline $\mathrm{O} 2 \mathrm{~A}^{\mathrm{i}}-\mathrm{Cu} 1-\mathrm{O} 2 \mathrm{~A}$ & 180.00 & $\mathrm{O} 2 \mathrm{~B}-\mathrm{Cu} 2-\mathrm{O} 2 \mathrm{~B}^{\mathrm{ii}}$ & 180.00 \\
\hline $\mathrm{O} 2 \mathrm{~A}-\mathrm{Cu} 1-\mathrm{N} 1^{\mathrm{i}}$ & $89.54(11)$ & $\mathrm{N} 3{ }^{\mathrm{ii}}-\mathrm{Cu} 2-\mathrm{O} 1 \mathrm{~B}$ & $91.42(12)$ \\
\hline $\mathrm{O} 2 \mathrm{~A}^{\mathrm{i}}-\mathrm{Cu} 1-\mathrm{N} 1^{\mathrm{i}}$ & $90.46(11)$ & $\mathrm{N} 3-\mathrm{Cu} 2-\mathrm{O} 1 \mathrm{~B}$ & $88.57(12)$ \\
\hline $\mathrm{O} 2 \mathrm{~A}^{\mathrm{i}}-\mathrm{Cu} 1-\mathrm{N} 1$ & $89.54(11)$ & $\mathrm{N} 3^{\mathrm{ii}}-\mathrm{Cu} 2-\mathrm{O} 1 \mathrm{~B}^{\mathrm{ii}}$ & $88.58(12)$ \\
\hline $\mathrm{O} 2 \mathrm{~A}-\mathrm{Cu} 1-\mathrm{N} 1$ & $90.46(11)$ & $\mathrm{N} 3-\mathrm{Cu} 2-\mathrm{O}_{1} \mathrm{~B}^{\mathrm{ii}}$ & $91.43(12)$ \\
\hline $\mathrm{N} 1-\mathrm{Cu} 1-\mathrm{O} 1 \mathrm{~A}^{\mathrm{i}}$ & $89.06(12)$ & $\mathrm{N} 3^{\mathrm{ii}}-\mathrm{Cu} 2-\mathrm{O} 2 \mathrm{~B}$ & $88.18(11)$ \\
\hline $\mathrm{N} 1-\mathrm{Cu} 1-\mathrm{O} 1 \mathrm{~A}$ & $90.94(12)$ & $\mathrm{N} 3^{\mathrm{ii}}-\mathrm{Cu} 2-\mathrm{O} 2 \mathrm{~B}^{\mathrm{ii}}$ & $91.82(11)$ \\
\hline $\mathrm{N} 1-\mathrm{Cu} 1-01 \mathrm{~A}^{\mathrm{i}}$ & $90.94(12)$ & $\mathrm{N} 3-\mathrm{Cu} 2-\mathrm{O} 2 \mathrm{~B}$ & $91.82(11)$ \\
\hline $\mathrm{N} 1-\mathrm{Cu} 1-\mathrm{O} 1 \mathrm{~A}$ & $89.06(12)$ & $\mathrm{N} 3-\mathrm{Cu} 2-\mathrm{O} 2 \mathrm{~B}^{\mathrm{ii}}$ & $88.18(11)$ \\
\hline $\mathrm{N} 1-\mathrm{Cu} 1-\mathrm{N} 1^{\mathrm{i}}$ & 180.00 & $\mathrm{~N} 3^{\mathrm{ii}}-\mathrm{Cu} 2-\mathrm{N} 3$ & 180.00 \\
\hline
\end{tabular}

Symmetry codes for IV:(i)-x,2-y,1-z; (ii)1-x,2-y,2-z

In the three compounds (I, II and III), atoms O2A, O1B, N1 and N3' occupy the equatorial sites of a distorted octahedral copper environment, with maximum deviations from the best plane of $0.054,0.045$ and $0.043 \AA$, and cation departures of $0.041,0.028$ and $0.033 \AA$, respectively. Atoms $\mathrm{O} 1 \mathrm{~A}$ and $\mathrm{O} 2 \mathrm{~B}$, in turn, occupy the slightly Jahn-Teller elongated apical positions, with $\mathrm{Cu}-\mathrm{O}$ vectors departing from the vertical to the best plane by $3.0^{\circ}$, $7.5^{\circ}$ in $\mathbf{I}, 2.2^{\circ}, 4.0^{\circ}$ in $\mathbf{I I}$ and $1.8^{\circ}, 4.5^{\circ}$ in III (Fig.3). 


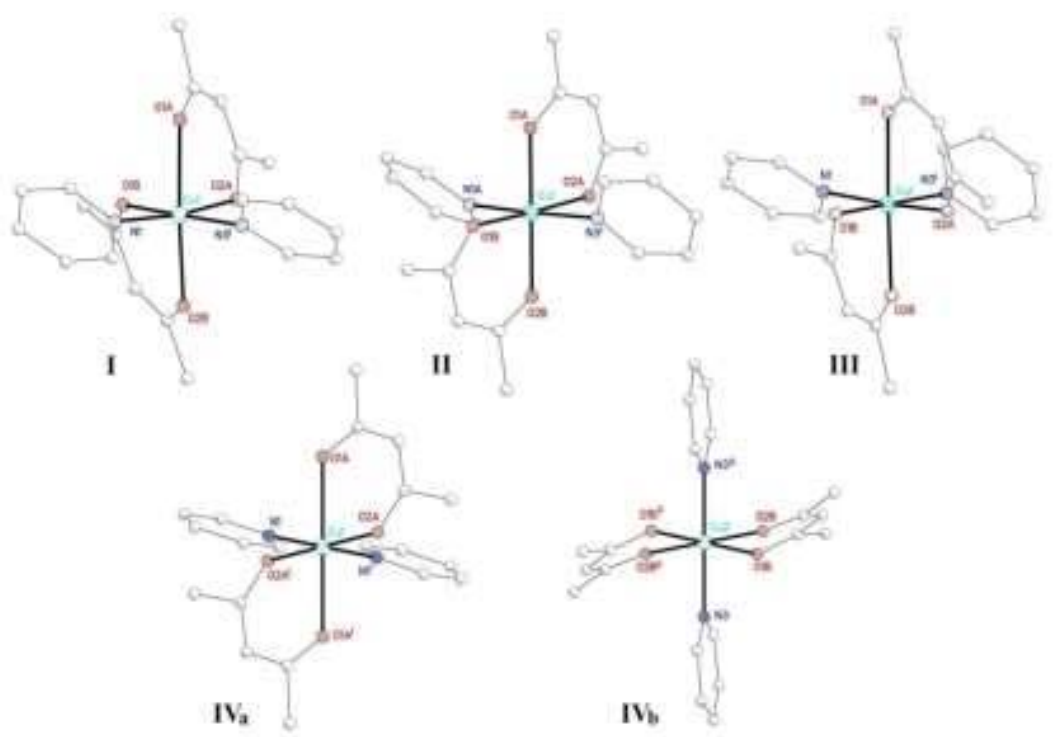

Fig 3: Detail of the copper atom, and its environment for compounds I to IV. The JahnTeller "contracted" effect is shown for the structure IV.

In compound IV the $\mathrm{CuO}_{4} \mathrm{~N}_{2}$ polyhedra (symmetric by inversion) are slightly different: the environment of $\mathrm{Cu} 1$ (IVa in Fig 3) is an octahedron with O2A, N1, O2A', N1' defining the base, and O1A,O1A' occupying the slightly elongated apical positions. Around $\mathrm{Cu} 2$, the situation is different, the "apparent" equatorial plane (see discussion below) being determined by the four hfacac oxygens atoms with similar distances to the cation, whereas the two nitrogens lie at slightly shorter ones (IVb in Fig 3). For both polyhedra, and due to symmetry constraints, the basal planes are perfectly planar, and contain the cation. Vertical deviations from the planes are $3.8^{\circ}$ and $2.3^{\circ}$, respectively.

It is to be noted that with these distances, the $\mathrm{Cu} 2$ octahedron (IVb in Fig 3) appears as a Jahn Teller "contracted" one, with a (shorter) N-Cu-N axis differentiating from two rather similar (and longer) $\mathrm{O}-\mathrm{Cu}-\mathrm{O}$ ones. This would constitute a rather infrequent case where the $\mathrm{Cu}(\mathrm{II})$ ground state degeneracy would be resolved through a z-contraction (rather than the usual z-expansion) leading to apical distances $\left(\mathrm{d}_{\mathrm{ap}}\right)$ shorter than the equatorial ones $\left(\mathrm{d}_{\mathrm{eq}}\right)$. In fact, a search of the Cambridge Structural Database (CSD version 5.36 with one update ${ }^{50}$ ) of $\mathrm{CuX}_{6}$ polyhedra $(\mathrm{X}: \mathrm{O}, \mathrm{N})$ disclosed 5514 cases with $\mathrm{d}_{\mathrm{ap}}>\mathrm{d}_{\mathrm{eq}}$, and only 295 with $\mathrm{d}_{\mathrm{ap}}<$ $\mathrm{d}_{\mathrm{eq}}$.

However, the real existence of such Jahn-Teller "contracted" polyhedra has been 
challenged on theoretical grounds; for instance in Halcrow (2003) ${ }^{51}$, where it is stated that very frequently these situations are just artefacts due to undisclosed disorder in the coordinating "equatorial" ligands, leading to deceiving distances and accordingly, false estimation of the real geometries. This is a fact which only a detailed analysis of the anisotropic atomic displacements factors can disclose. In an extremely brief summary (for a thorough explanation see for instance, Hirschfeld, $1976^{52}$; Dunitz et al., $1988^{53}$, etc.) this type of disorder would be revealed by large $\mathrm{Cu}-\mathrm{X} \Delta \boldsymbol{m s} \boldsymbol{s} \boldsymbol{a}$ values (X: N, O), $\Delta \boldsymbol{m s} \boldsymbol{s} \boldsymbol{a}$ being the difference between mean-square displacement amplitudes of the $\mathrm{Cu}, \mathrm{X}$ coordinated atoms, as measured along the bond. In a "normal" situation, these $\Delta$ values ought to be small. A usual criterium to define $\Delta$ values as "abnormal" (e.g., in the multipurpose program PLATON ${ }^{40}$ ) is to mark as such those values fulfilling the condition $\Delta / \sigma(\Delta)>5$. Tables 4 and 5 present relevant values for the environment around $\mathrm{Cu} 1$ and $\mathrm{Cu} 2$ in structure IV. It is apparent from the entries therein that, at least with the above mentioned criteria, there are no grounds for objection to the coordination distances in the "elongated" Jahn-Teller octahedron around $\mathrm{Cu} 1$, while $\mathrm{Cu}-\mathrm{O}$ distances in the "contracted" one around $\mathrm{Cu} 2$ are to be considered highly suspect, with $\Delta / \sigma(\Delta)$ values larger than 10 and throwing a reasonable doubt about the real geometry of the polyhedron.

A rather similar case to the one herein presented has been analyzed in the above referenced paper by Halcrow (2003) ${ }^{51}$, where a structure refinement at $\mathrm{T}=30 \mathrm{~K}$ allowed to "freeze" the dynamical disorder and thus resolve the seemingly equal "pseudo equatorial" distances into a longer and a shorter ones, in a well differentiated $\mathrm{Cu}-\mathrm{X}$ pair, the equatorial plane being thus redefined and leading to an "orthodox" elongated Jahn-Teller scheme.

Given the analogy in geometry and metrics between Halcrow's case and the one presented above, and according to the impossibility to perform a similar analysis at $\mathrm{T}=30 \mathrm{~K}$, we can only claim a reasonable state of doubt about the real geometry around $\mathrm{Cu} 2$, as given by our $150 \mathrm{~K}$ diffraction experiments.

The $h f a c a c$ anions are similar in all four compounds, both metrically as well as in their $\kappa^{2}$ $\mathrm{O}, \mathrm{O}^{\prime}$ chelating behaviour. In the case of the room temperature structures I and II, they also share the rotational disorder in the $\mathrm{CF}_{3}$ groups (see Refinement Section for details).

There are, however some differences in the way the anions approach the cation, in 
particular their "slanting angle", or the "inclination" with which the ligand approaches the metal centre and which can be measured by the dihedral angle subtended by the $\mathrm{O}-\mathrm{Cu}-\mathrm{O}$ coordination plane and the ligand mean plane, which amount $18.1^{\circ}, 22.8^{\circ}$ in $\mathbf{I}, 3.9^{\circ}, 9.0^{\circ}$ in II, $18.9^{\circ}, 17.8^{\circ}$ in III, $14.2^{\circ}, 23.0^{\circ}$ in IV. These differences do not seem to be the result of local steric hindrance in the coordination polyhedral (for instance, there is no clear correlation of this approach to the cation and the cis or trans coordination of the terpyridyl linker) and may result just from packing requirements.

Table 5.

msda analysis for the $\mathrm{Cu}(\mathrm{II})$ coordination polyhedra in compound IV.

\begin{tabular}{lllll}
\hline Bond & $\mathrm{d}_{(\mathrm{Cu}-\mathrm{X})}(\AA)$ & $\Delta(\boldsymbol{m s d a})\left(\AA^{2}\right)$ & $\Delta / \sigma(\Delta)$ & $\operatorname{Sqrt}(\Delta)(\AA)$ \\
\hline Cu1-O1A & $2.268(3)$ & $0.0082(18)$ & 4.55 & 0.0906 \\
$\mathrm{Cu} 1-\mathrm{O} 2 \mathrm{~A}$ & $2.011(3)$ & $0.0052(16)$ & 3.25 & 0.0721 \\
$\mathrm{Cu} 1-\mathrm{N} 1$ & $2.034(3)$ & $0.0009(17)$ & 0.53 & 0.0300 \\
$\mathrm{Cu} 2-\mathrm{O} 1 \mathrm{~B}$ & $2.129(3)$ & $0.0229(18) \#$ & 12.72 & 0.1513 \\
$\mathrm{Cu} 2-\mathrm{O} 2 \mathrm{~B}$ & $2.135(3)$ & $0.0190(17) \#$ & 11.18 & 0.1378 \\
$\mathrm{Cu} 2-\mathrm{N} 3$ & $2.010(3)$ & $0.0020(17)$ & 1.18 & 0.0447 \\
\hline
\end{tabular}

This same type of strain seems to be the cause why all the terpyridyl ligands (4-stpy in I, 4qtpy in II, 3-qtpy in III and 4-cntpy in IV) appear significantly deformed, deviating largely from planar arrangements. This can be assessed by the values presented in Table 6 .

From the rather low values in Table 4 it is apparent that the main responsible for the deformation is the quasi-free rotation, with a rather low bending component. The coplanarity of the pyridine rings of the terpyridine moiety, is directly related with the magnetic interaction as discussed in Magnetic Properties. 
Table 6.

Deformation angles $\left({ }^{\circ}\right)$ in the terpyridyl ligands for compounds I, II, III and IV. (The geometry is defined as Plane(a)-Axis-Plane (b))

\begin{tabular}{ccccc}
\hline & \multicolumn{1}{c}{ I } & II & III & IV \\
& (4-stpy) & (4-qtpy) & (3-qtpy) & (4-cntpy) \\
\hline Plane(a)-Plane(b) & \multicolumn{4}{c}{ Total interplanar angle $\left(^{\circ}\right)$} \\
$\mathbf{2 - 1}$ & $41.1(2)$ & $18.9(3)$ & $16.58(14)$ & $19.1(2)$ \\
$\mathbf{2 - 3}$ & $33.8(2)$ & $26.0(3)$ & $25.68(15)$ & $16.3(2)$ \\
$\mathbf{2 - 4}$ & $28.2(3)$ & $42.5(3)$ & $50.72(15)$ & $7.74(18)$ \\
$\mathbf{2 - 5}$ & n.a & $43.3(3)$ & $51.40(17)$ & n.a \\
\hline
\end{tabular}

For Ring Codes, see Figs 1 and 2.

Regarding the coordination modes, the nitrogenated ligands act in all cases as $\mu_{2} \kappa^{2}-N, N^{\prime}$ bidentate bridging linkers, binding to the cation in a cis mode in structures I and III, while in a trans fashion in II and IV. In all four structures they define undulating chains (Fig 4) running along [100] in I (the symmetry operation building the chain is the $1+x, y, z$ translation) and III (generated by a twofold screw, 1/2+x,1/2-y,-z), along [010] in II (by way of twofold screw, $-\mathrm{x},-1 / 2+\mathrm{y}, 1 / 2-\mathrm{z}$ ) and along [101] in IV (through the consecutive application of the -x,2-y,1-z and 1-x,2-y,2-z inversions ).

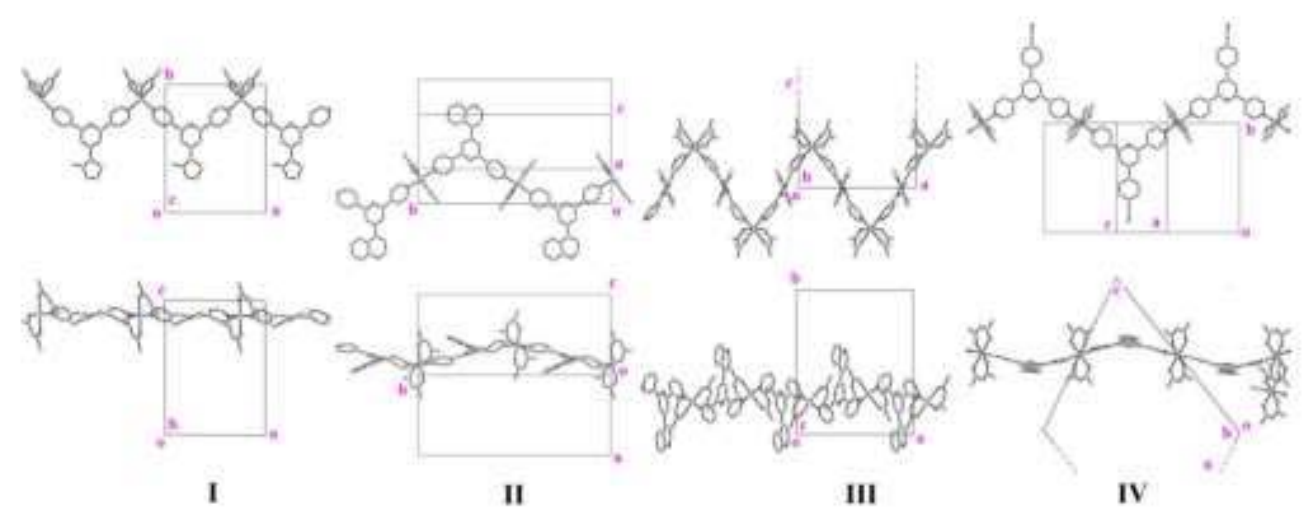

Fig.4: The different kinds of chains generated for I-IV.

A common factor to the interactions between chains is the fact that they are weak and diverse. Tables S1 to S4 provide a survey of the most relevant interactions (Table S1: Hydrogen bonding; Table S2: $\pi \ldots \pi$, Table S3: F...F and Table S4: C-F... $\pi$ interactions). 
This diversity of binding interactions as well as the diversity of chain shapes has a profound effect in the packing arrangement. (Fig.S4 and S5).

The $\mathrm{Cu} \cdots \mathrm{Cu}$ distances, both along the chains as well as between neighbouring chains, are rather similar within the series, viz structure I: 12.243 and $7.949 \AA$ ), II: 12.669 and 7.084 Å); III: 13.109 and $8.044 \AA$ )); IV: 12.462 and $6.990 \AA$.

At this stage it is interesting to highlight the structural differences between II and III, which share the same cation, same anion and similar reaction conditions, and only differ in the N-site substitution of the bridging agent 4-qtpy in II and 3-qtpy in III (see Scheme 1). As already stated, the environment around the $\mathrm{Cu}$ (II) centers in both compounds are totally different, compound II exhibiting a trans disposition of pyridyl units while III binds in a cis mode. There are also some differences in the shape of the almost identical ligands, revealed in a diverse out-of-plane deformation of 4-qtpy and 3-qtpy (see Table 6). Finally, the extremely different coordination affects not only the chain shapes (see Fig 3) but also the interchain interactions and accordingly, their 3D disposition: in spite that both compounds present the same quinoline system, an efficient $\pi \cdots \pi$ interaction linking chains appears only in III (see Table S2), the undulating 1D structures in II being mainly associated by weak fluorine interactions (see Table S3).

These significant structural differences setting both polymers apart are just the result of the change in the directionality of the $\mathrm{N}$-donor atoms; this is a clear example of how one single reaction variable can play a crucial role in governing the geometry and topology of the resulting products.

\subsection{Thermogravimetry and Powder XRD}

To investigate the thermal stability of compounds $\mathbf{I}-\mathbf{I V}$, thermogravimetric analyses were performed on solid samples consisting of numerous single crystals in the $30-550{ }^{\circ} \mathrm{C}$ range under a nitrogen atmosphere at a heating rate of $10^{\circ} \mathrm{C} \mathrm{min}^{-1}$ (Fig. S6 shows the TGA and DTG curves). As expected, the decomposition of coordination polymers I-IV are very similar since they have similar structures. 
It can be observed that the structure of compound I remains stable up to $260^{\circ} \mathrm{C}$; in the range $263-300^{\circ} \mathrm{C}$ the structure starts to collapse, with a single-step weight loss of $57 \%$ attributed to the continuous decomposition process of the organic ligands, hfacac and 4-stpy.

For compounds II and III, a first weight-loss process occurs at $60^{\circ} \mathrm{C}$ and $180^{\circ} \mathrm{C}$ respectively, which can be attributed to the loss of one chloroform solvent molecule included in the crystal structure. (Found: $10.6 \%$ in II and $12.2 \%$ in III, calcd $12.47 \%$ ). Subsequent to this, the TG curves of II and III exhibit a rapid weight-loss process at 280$300^{\circ} \mathrm{C}$ and $266^{\circ} \mathrm{C}$, respectively, attributed to the partial decomposition of the organic hfacac and terpyridine components (3-qtpy and 4-qtpy) (Found: 41\%) followed by a continuous decomposition process of the residual products continuing until our limiting temperature of $550^{\circ} \mathrm{C}$.

Compound IV remains stable up to $200^{\circ} \mathrm{C}$. After that, the structure gradually loses weight showing two decomposition steps at $276^{\circ} \mathrm{C}$ and $345^{\circ} \mathrm{C}$ due to the decomposition of organic ligands, hfacac and 4-cntpy (Found: 29 and 22\%, respectively); this process continues until our limiting temperature.

The thermal properties of coordination compounds are determined by the chemical properties of the metal center and coordinated ligands. The experimental data of decomposition temperatures of the precursors, 4-stpy, 4-qtpy, 3-qtpy and 4-cntpy ligands are: $363^{\circ} \mathrm{C}, 384.3^{\circ} \mathrm{C}, 408^{\circ} \mathrm{C}$ and $391{ }^{\circ} \mathrm{C}$, respectively ${ }^{33}$ and for the metallic precursor $\mathrm{Cu}(\text { hfacac })_{2}, 121^{\circ} \mathrm{C}$. (Fig. $\mathbf{S 7}$ and $\left.\mathbf{S 8}\right)$.

Details of the thermal decomposition mechanism and the possibility of different intermediate species for Compound I-IV are very difficult to speculate, considering that the decomposition process is continuous and gradual. ${ }^{54-56}$ However, based on the experimental data mentioned above, it is expected that the $\beta$-diketonate ligand decomposes completely much earlier than the terpyridine ligands.

To confirm that the crystal structures are truly representative of the bulk materials, X-ray powder diffraction experiments (XRPD) were carried out for I-IV. The experimental and computer-simulated XRPD patterns (see Fig. S9) of the corresponding compounds show that the synthesized bulk materials are the same as the single crystals, except for II, in which the poor agreement comes from the instability of the crystal under ambient conditions, the sample rapidly turning opaque. 


\subsection{UV-Visible Absorption and Emission properties}

In order to get more information about the frontier orbitals involved in the electronic transitions, the photophysical properties of complexes I-IV have been investigated in solvent solution and solid state.

Absorption spectra for compounds I-IV in air-saturated $\mathrm{CH}_{2} \mathrm{Cl}_{2}$ solutions are shown in Fig. 5a. For complexes I-III, a wide band with two maxima at $275 \mathrm{~nm}$ and $310 \mathrm{~nm}$ can be seen, while compound IV presents an absorption band centered at $265 \mathrm{~nm}$ with a shoulder at 310 $\mathrm{nm}$. The independence of the absorption maxima on solvent polarity and the comparison with the spectral features of the pure ligands in solution, allow us to postulate that the electron transition involved has $\pi \rightarrow \pi^{*}$ character. $^{33}$ On the other hand, emission measurements have been carried out both in solution and in solid state (see Fig. 5b and Fig. S10).

i) Emission Spectra in Solution: As can be seen from Fig. 5b for terpyridyl complexes dissolved in aerated $\mathrm{CH}_{2} \mathrm{Cl}_{2}$, upon excitation at $310 \mathrm{~nm}$, emission bands with similar maxima (around $380 \mathrm{~nm}$ ) can be appreciated for compounds I-III, while complex IV exhibits a more intense band with a maximum at higher energy $(358 \mathrm{~nm})$. Table 7 summarizes the main photophysical properties. The emission quantum yield value $\left(\Phi_{\mathrm{em}}\right)$ for IV is at least one order of magnitude higher than the values of I-III. The small Stokes shift can be explained due to the $\pi \rightarrow \pi^{*}$ intramolecular transition.
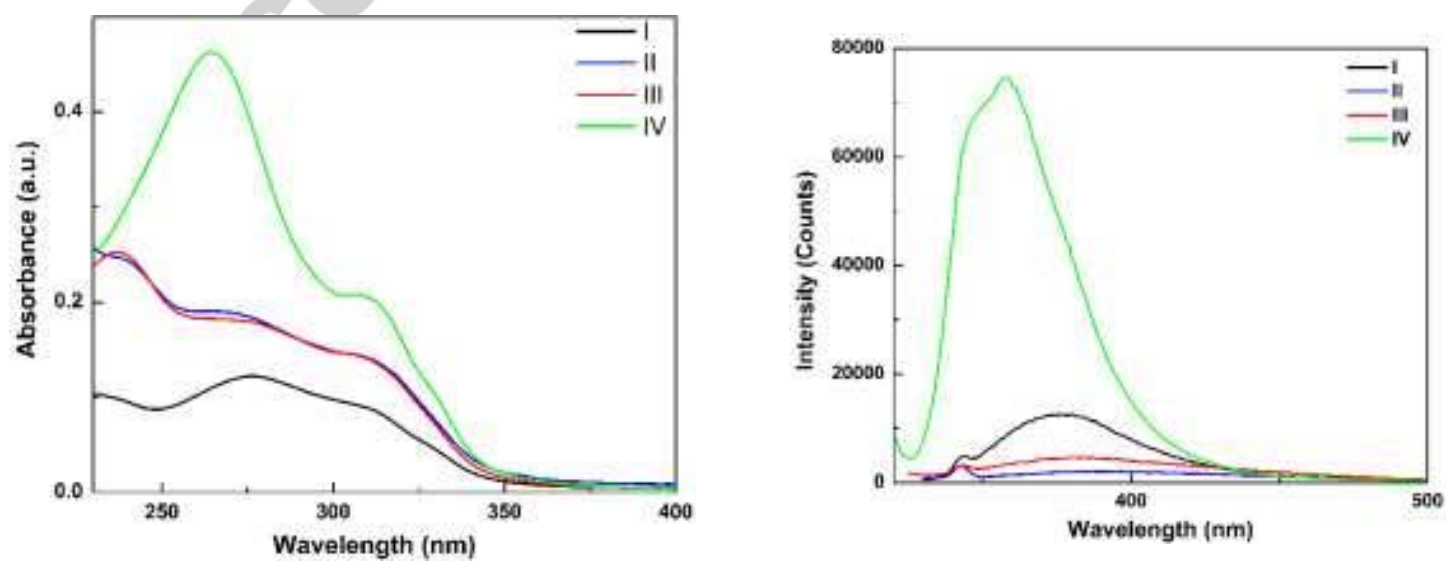

Fig. 5. a) left, absorption and b) right, emission spectra of I-IV in air-saturated $\mathrm{CH}_{2} \mathrm{Cl}_{2}$ solutions. 
Table 7. Summary of spectroscopic characterization of I-IV in air-saturated $\mathrm{CH}_{2} \mathrm{Cl}_{2}$ solution and solid state.

\begin{tabular}{|c|c|c|c|c|c|}
\hline & Absorption & & Em & ion & \\
\hline Compound & $\begin{array}{c}\lambda_{\max }\left(\varepsilon / 10^{3} \mathrm{M}^{-1} \mathbf{c m}^{-1}\right)^{\mathbf{a}} \\
(\text { solution })\end{array}$ & $\begin{array}{c}\lambda_{\max }{ }^{a} \\
\text { (solution) }\end{array}$ & $\begin{array}{c}\Phi_{\mathrm{em}}\left(\mathbf{1 0}^{-2}\right)^{\mathrm{b}} \\
\text { (solution) }\end{array}$ & $\begin{array}{c}\tau(\mathbf{p s}) \\
\text { (solution) }\end{array}$ & $\begin{array}{c}\tau(\mathbf{p s}) \\
\text { (solid state) }\end{array}$ \\
\hline I & $\begin{array}{l}278 \mathrm{~nm}(39.0) \\
310 \mathrm{~nm}(32.0)\end{array}$ & $376 \mathrm{~nm}$ & 7.1 & $<600$ & $<600$ \\
\hline II & $\begin{array}{l}275 \mathrm{~nm}(34.5) \\
310 \mathrm{~nm}(33.6)\end{array}$ & $390 \mathrm{~nm}$ & 1.1 & $<600$ & $\begin{array}{l}1700(86 \%) \\
6600(14 \%)\end{array}$ \\
\hline III & $\begin{array}{l}275 \mathrm{~nm}(23.5) \\
310 \mathrm{~nm}(22.0)\end{array}$ & $382 \mathrm{~nm}$ & 0.2 & $<600$ & $<600$ \\
\hline IV & $\begin{array}{l}265 \mathrm{~nm}(62.0) \\
310 \mathrm{~nm}(29.0)\end{array}$ & $358 \mathrm{~nm}$ & 28.0 & 750 & $<600$ \\
\hline
\end{tabular}

${ }^{\mathrm{a}}$ Excitation at $310 \mathrm{~nm} .{ }^{\mathrm{b}}$ Errors were below 10\%.

The similarities between the absorption and emission spectra obtained for the complexes in solution with those measured for the free ligands, ${ }^{33}$ suggest that the coordination polymers dissociate when they are dissolved. Then, the absorption and emission properties evaluated in solution would correspond only to the free ligands. Moreover, taking into account that the absorption spectra calculated theoretically are similar to the experimental ones (Fig. S11), we can conclude that the lower energy electronic transition for the complexes involves mainly the ligand orbitals. As can be seen from Fig. 6a, the frontier orbitals from DFT calculations for compound I-III in solution (relax geometry), show that the HOMOs have the electronic density localized mainly on the pyridine central ring and the substituent, while the HOMO for IV is located on the tpy moiety. For all compounds the LUMOs are delocalized over the entire molecule. Therefore, the HOMO-LUMO transition for Compound I-IV should be ascribed to a mixture of $\pi \rightarrow \pi^{*} /$ ILCT characters, which is consistent with their UV-Vis absorption assignments.

The emission properties of the free ligands (or dissociated compounds I-IV) in solvent solution are influenced significantly by the different aryl substituent. Upon excitation at $310 \mathrm{~nm}$, the emission bands of compounds I-III exhibit a slight red-shifted, having low quantum yield values (see Table 7). Meanwhile, compound IV bearing an electron- 
withdrawing substituent on the tpy moiety, emits at higher energy with the highest quantum yield. ${ }^{57,58}$ This could be attributed to a major IL charge transfer character for free ligand of IV in comparison to those for I-III.

ii) Emission Spectra in Solid State: Upon excitation at $280 \mathrm{~nm}$, there are no emissions observed for Compounds I, III and IV, and only compound II has an emission band centered at $420 \mathrm{~nm}$ (see Fig S10). Then, it was considered that compounds I-IV in the solid state correspond to 1D covalent polymers and therefore, other factors such as: metal ion, structural parameters (torsion angles) and intermolecular interaction, play a crucial role in their emission solid state properties. ${ }^{20}$

The results demonstrate that the emission of I, III and IV in solid state is quenched with luminescent lifetime values below the limit of the equipment, while compound II has a biexponential emission decay as typically found for conformationally constrained systems (see Table 7) Then, this may be ascribed to the coordination of $\mathrm{Cu}^{2+}$ which disfavors the radiative emission with ILCT character. Fig. 6b shows the molecular orbital surfaces, HOMOs and LUMOs, in solid state.

The electron density in the HOMO for compound I and II is centered mainly on the substituent and the central ring of tpy. By contrast, the electron density for compounds III and IV is localized on the tpy moiety, which would be affected by the coordination of the metal ion. However, in order to find a structural relationship that explains the luminescence phenomenon, it is necessary to conduct thorough studies involving a larger number of experiences and measurements. 


\section{Solution}

(a)
Solid State

(b)
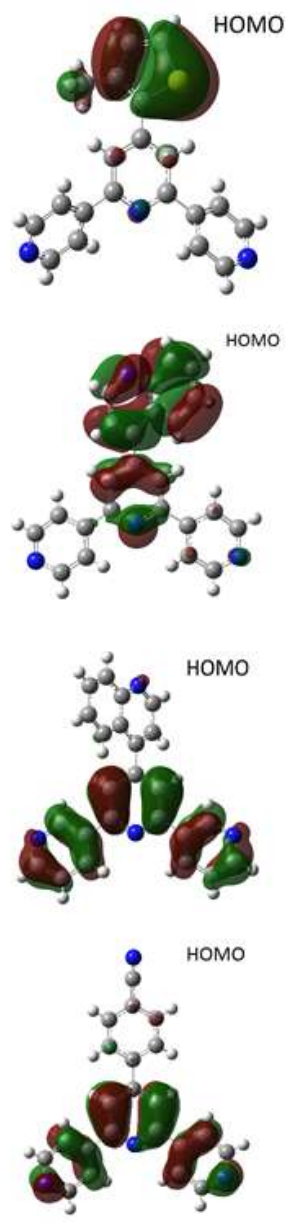
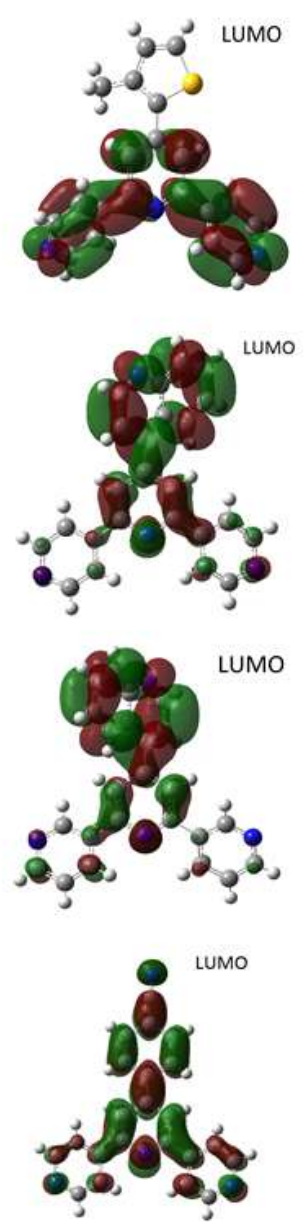

Fig. 6: a). Optimized HOMOs and LUMOs molecular orbital surfaces for compounds I-IV in solution (relax geometry). b) HOMOs and LUMOs molecular orbital surfaces for compounds I-IV (in solid state).

\subsection{Magnetic Properties}

The values for the magnetic moments for the compounds $\mathrm{Cu}(4-$ stpy)(hfacac) $2,(\mathrm{I}), \mathrm{Cu}(4-$ qtpy)(hfacac) $)_{2}$, (II) and $\mathrm{Cu}(3-\mathrm{qtpy})(\mathrm{hfacac})_{2}$, (III) were obtained through the inverse molar susceptibility (after subtraction of the diamagnetic core contribution and sample holder signal) plotted versus temperature.

The effective moments $\mu_{\text {eff }}$ were then evaluated by the Curie-Weiss expression $\mu_{\text {eff }}^{2}=8 \mathrm{C} / \mathrm{n}$, where $\mathrm{C}$ is the Curie constant and $\mathrm{n}$, the number of magnetic centers. In our case, $\mathrm{n}$ 
corresponds to 2 non interacting $\mathrm{S}=1 / 2$ spins of the $\mathrm{Cu}^{2+}$ cation. The magnetic moments thus obtained are $\mu_{\mathrm{eff}}(\mathrm{I})=1.81, \mu_{\mathrm{eff}}(\mathrm{II})=1.87$ and $\mu_{\mathrm{eff}}(\mathrm{III})=1.80 \mu_{\mathrm{B}} /$ f.u., for compounds $\mathbf{I}$, II and III respectively. In theory, the magnetic moment for only-one spin corresponds to $1.73 \mu_{\mathrm{B}}$ but, due to different factors, such as orbital contribution or covalent bonds, the effective moment value may range from 1.8 to $2.2 \mu_{\mathrm{B}} \cdot{ }^{59}{ }^{60}$ The structural data supports these values since the copper cations are situated rather apart, with no interactions between them, implying a simple paramagnetic behavior (as shown in Fig. S12).

\section{Cu(4-cntpy)(hfacac) 2 (IV)}

The situation is quite different for compound (IV) $\mathrm{Cu}(4-\mathrm{cntpy})(\text { hfacac) })_{2}$ as shown in Fig.7 in which the $\chi_{M} \cdot T$ product is plotted against temperature. At room temperature, $\chi_{M} \cdot T$ has a value of 0.797 emu.K.mol ${ }^{-1}$, which corresponds to an effective moment of $1.78 \mu_{\mathrm{B}}$. This value is close to the expected magnetic moment for two non-interacting spins $S=1 / 2\left(\mu_{\text {eff }}=\right.$ $\left.1.73 \mu_{\mathrm{B}}\right)$. However, below $100 \mathrm{~K}$, this product decreases with decreasing temperature, indicating antiferromagnetic interactions.

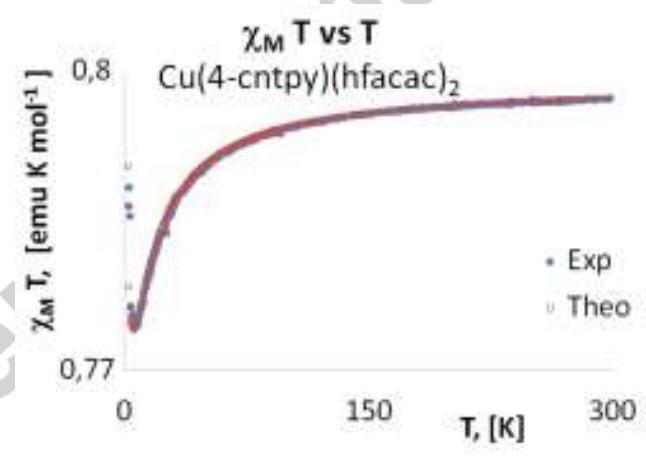

Fig. 7: Temperature dependence of $\chi \mathrm{T}$ for $\mathrm{Cu}(4-\mathrm{cntpy})(\mathrm{hfacac})_{2}$.

To explain this interaction, we used an isotropic model between two $S=1 / 2$ copper centers. The phenomenological Hamiltonian accounting for this may be written as:

$$
H=-J S_{A} \cdot S_{B}
$$

where $\mathbf{J}$ stands for the exchange coupling. In this model, the magnetic susceptibility can be derived from the Bleaney-Bowers equation, Eq. $2 .{ }^{61}$

$$
\chi=\frac{2 N g^{2} \beta^{2}}{k T[3+\exp (-J / k T)]} \cdot(1-\rho)+\frac{N g^{2} \beta^{2}}{2 k T} \cdot \rho
$$


where all symbols have their usual meaning $(N, k, \beta$ and $g$ are, respectively, the Avogadro's number, the Boltzmann's constant, the Bohr magneton and the Landé g-factor) whereas $\rho$ is the molar fraction of uncoupled species. Using the above relations, the best fit to the experimental data, as shown in Fig. 7, yielded $g=2.06, J=-4.38 \mathrm{~cm}^{-1}, \rho=0.07$ and $\mathrm{R}=$ $1.0 \cdot 10^{-6}$, where $\mathrm{R}$ is defined as $\mathrm{R}=\Sigma\left[\left(\chi_{\mathrm{M}}\right)_{\mathrm{obs}}-\left(\chi_{\mathrm{M}}\right)_{\text {cal }}\right]^{2} / \Sigma\left[\left(\chi_{\mathrm{M}}\right)_{\mathrm{obs}}\right]^{2}$. It is important to note that, even though the structural description points toward a chain formation of copper centers and a subsequent magnetic interaction along the chain, attempts to fit the experimental data using a chain model ${ }^{62}$ were unsuccessful.

One possible explanation of why only compound IV exhibits a magnetic interaction, could be due to its shorter $\mathrm{Cu} \cdots \mathrm{Cu}$ distances; in particular a shortest interchain distance, could be responsible of the observed cooperative behavior. However, these distances, both along the chains as well as between neighbouring chains, are rather similar within the series, viz structure I: $12.243(2)$ and 7.949(2) $\AA$ ), II: 12.669(3) and 7.084(3) $\AA$ ); III: 13.109(1) and 8.044(1) A); IV: 12.462(2) and 6.990(2). Therefore a second variable should be taken into account. This structural variable is the dihedral angle between the pyridine rings.

We believe that, the greater the planarity of the pyridine rings, the better would be the interaction between magnetic orbitals, as suggested by the lower value of the dihedral angles. Scheme 3, here below, represents the dihedral angle between the pyridine rings and its value for the four compounds treated in this work (rings codes as defined in Figs. 1 and 2). The compound IV has the lowest torsion angles, $\delta$ and $\delta$; therefore, it is the flattest of the four compounds (as deduced from Table 6).

The planarity of the ligands is directly related to the overlap between the molecular orbitals $^{62}$ involved in the magnetic interaction, so this structural parameter may explain the observed behavior of the magnetic properties. Finally, we think that the coplanarity of the pyridine rings is the most important structural factor to explain the cooperative interaction between copper atoms. ${ }^{63}$ This type of relationship between dihedral angles and magnetic behavior has been studied, among other research groups, by Álvarez et al. ${ }^{64,65}$ 


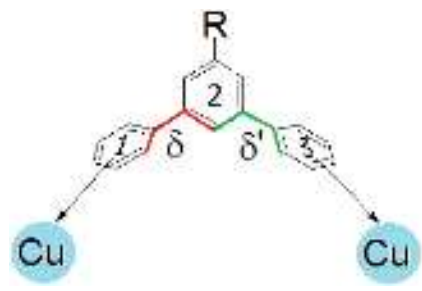

Scheme 3. Representation of coplanarity between aromatic rings

\section{Conclusion}

Four $\mathrm{Cu}^{\mathrm{II}}$ coordination compounds, I-IV, were successfully synthesized using substituted $4,2^{\prime}: 6^{\prime}, 4^{\prime \prime}$ and 3,2':6',3'-tpy ligands, where the 3-qtpy is a new tpy derivate. These compounds result in 1-D chains associated very differently. II and III were obtained under the same reaction conditions, except that the substitution pattern changed from $4,2^{\prime}: 6^{\prime}, 4^{\prime \prime}-$ to 3,2 ':6',3"-tpy in the ligand. This study is a novel example in which this sole variable reaction plays a crucial role in the structural diversity of the coordination polymers. The structural parameters of the crystalline samples and their theoretical molecular orbitals, are very important to understand the physical properties (both magnetic and fluorescent) of these systems. The analysis of the magnetic data of compounds I, II and III reveals a simple paramagnetic behavior. Complex IV shows a weak antiferromagnetic interaction with $\mathrm{J}=-4.38 \mathrm{~cm}^{-1}$ (with less than $7 \%$ of uncoupled species) due to a better overlap between molecular orbitals which control the interaction between copper centers. This overlap is related to the coplanarity of the pyridine rings of the terpyridine ligand which connect the magnetic centers. A deeper analysis on this point would involve theoretical calculations on the value of $J$ (e.g. DFT calculation), which depends on the overlap of the magnetic orbitals involved. It would be an interesting challenge in later studies on tpy-transition metal systems.

\section{Acknowledgements}

This research was performed as part of the Chilean-French International Associated Laboratory for "'Inorganic Functional Materials', (LIA-MIF-CNRS N'836). Financial supports FONDECYT (Chile), grant No: 1130433 (Y.Moreno), UNAB DI-773-15/R, the CNRS and the Université de Rennes-1 are gratefully acknowledged. Thanks to CONICYT (Chile) for support of graduate fellowships $\mathrm{N}^{\circ}: 21120148$ (D.Toledo). 


\section{References}

1. E. C. Constable, Chemical Society Reviews, 2007, 36, 246-253.

2. U.S. Schubert, H. Hofmeier and G. R. Newkome, Modern Terpyridine Chemistry, Wiley-VCH, Weinheim, 2006.

3. U. S. Schubert, A. Winter and G. R. Newkome, Terpyridine-Based Materials: For Catalytic, Optoelectronic and Life Science Applications, Wiley-VCH, 2011.

4. A. Wild, A. Winter, F. Schlutter and U. S. Schubert, Chemical Society Reviews, 2011, 40, 1459-1511.

5. F. Yuan, R. An, H.-M. Hu, S.-S. Shen, X. Wang, M.-L. Yang and G. Xue, Inorganic Chemistry Communications, 2015, 56, 1-4.

6. L. Zhang, C.-J. Li, J.-E. He, Y.-Y. Chen, S.-R. Zheng, J. Fan and W.-G. Zhang, Journal of Solid State Chemistry, 2016, 233, 444-454.

7. K. R. Reddy, W. Park, B. C. Sin, J. Noh and Y. Lee, Journal of Colloid and Interface Science, 2009, 335, 34-39.

8. K. R. Reddy, B. C. Sin, C. H. Yoo, W. Park, K. S. Ryu, J.-S. Lee, D. Sohn and Y. Lee, Scripta Materialia, 2008, 58, 1010-1013.

9. K. R. Reddy, K.-P. Lee and A. I. Gopalan, Journal of Applied Polymer Science, 2007, 106, 1181-1191.

10. C. E. Housecroft, Dalton Transactions, 2014, 43, 6594-6604.

11. C. E. Housecroft, CrystEngComm, 2015, 17, 7461-7468.

12. Y. M. Klein, A. Prescimone, E. C. Constable and C. E. Housecroft, Polyhedron, 2016, 103, Part A, 58-65.

13. M.-S. Wang, M.-X. Li, X. He, M. Shao and Z.-X. Wang, Inorganic Chemistry Communications, 2014, 42, 38-41.

14. F. Yuan, Q.-E. Zhu, H.-M. Hu, J. Xie, B. Xu, C.-M. Yuan, M.-L. Yang, F.-X. Dong and G.-L. Xue, Inorganica Chimica Acta, 2013, 397, 117-123.

15. Y. Maximilian Klein, E. C. Constable, C. E. Housecroft and A. Prescimone, CrystEngComm, 2015, 17, 2070-2073.

16. J. Granifo, R. Gaviño, E. Freire and R. Baggio, Acta Crystallographica Section C, 2012, 68, m269-m274.

17. J. Granifo, R. Gaviño, E. Freire and R. Baggio, Journal of Molecular Structure, 2011, 1006, 684-691.

18. Z. Yin, S. Zhang, S. Zheng, J. A. Golen, A. L. Rheingold and G. Zhang, Polyhedron, 2015, 101, 139-145.

19. F. Allen, Acta Crystallographica Section B, 2002, 58, 380-388.

20. E. C. Constable, C. E. Housecroft, M. Neuburger, J. Schönle, S. Vujovic and J. A. Zampese, Polyhedron, 2013, 60, 120-129.

21. E. C. Constable, C. E. Housecroft, J. Schönle, S. Vujovic and J. A. Zampese, Polyhedron, 2013, 62, 260-267.

22. E. C. Constable, C. E. Housecroft, M. Neuburger, S. Vujovic, J. A. Zampese and G. Zhang, CrystEngComm, 2012, 14, 3554-3563.

23. O. M. Yaghi, M. O'Keeffe, N. W. Ockwig, H. K. Chae, M. Eddaoudi and J. Kim, Nature, 2003, 423, 705-714.

24. L.-H. Cao, Q.-Q. Xu, S.-Q. Zang, H.-W. Hou and T. C. W. Mak, Crystal Growth \& Design, 2013, 13, 1812-1814. 
25. J. Heine, J. Schmedt auf der Günne and S. Dehnen, Journal of the American Chemical Society, 2011, 133, 10018-10021.

26. J. Costa, R. Ruloff, L. Burai, L. Helm and A. E. Merbach, Journal of the American Chemical Society, 2005, 127, 5147-5157.

27. Y.-L. Gai, F.-L. Jiang, L. Chen, Y. Bu, M.-Y. Wu, K. Zhou, J. Pan and M.-C. Hong, Dalton Transactions, 2013, 42, 9954-9965.

28. Q.-R. Wu, J.-J. Wang, H.-M. Hu, Y.-Q. Shangguan, F. Fu, M.-L. Yang, F.-X. Dong and G.-L. Xue, Inorganic Chemistry Communications, 2011, 14, 484-488.

29. B.-C. Wang, Q.-R. Wu, H.-M. Hu, X.-L. Chen, Z.-H. Yang, Y.-Q. Shangguan, M.L. Yang and G.-L. Xue, CrystEngComm, 2010, 12, 485-492.

30. M. Barquín, J. Cancela, M. J. González Garmendia, J. Quintanilla and U. Amador, Polyhedron, 1998, 17, 2373-2378.

31. E. C. Constable, G. Zhang, E. Coronado, C. E. Housecroft and M. Neuburger, CrystEngComm, 2010, 12, 2139-2145.

32. M. Wałęsa-Chorab, A. Gorczyński, M. Kubicki, M. Korabik and V. Patroniak, Polyhedron, 2013, 54, 260-271.

33. D. Toledo, R. Baggio, E. Freire, A. Vega, N. Pizarro and Y. Moreno, Journal of Molecular Structure, 2015, 1102, 18-24.

34. J. Wang and G. S. Hanan, Synlett, 2005, 8, 1251-1254.

35. Y. Xi, W. Wei, Y. Xu, X. Huang, F. Zhang and C. Hu, Crystal Growth \& Design, 2015, 15, 2695-2702.

36. G. A. Crosby and J. N. Demas, The Journal of Physical Chemistry, 1971, 75, 9911024.

37. M. J. T. Frisch, G. W.; Schlegel, H. B.; Scuseria, G. E.; Robb, M. A.; Cheeseman, J. R.; Scalmani, G.; Barone, V.; Mennucci, B.; Petersson, G. A.; Nakatsuji, H.; Caricato, M.; Li, X.; Hratchian, H. P.; Izmaylov, A. F.; Bloino, J.; Zheng, G.; Sonnenberg, J. L.; Hada, M.; Ehara, M.; Toyota, K.; Fukuda, R.; Hasegawa, J.; Ishida, M.; Nakajima, T.; Honda, Y.; Kitao, O.; Nakai, H.; Vreven, T.; Montgomery, J. A., Jr.; Peralta, J. E.; Ogliaro, F.; Bearpark, M.; Heyd, J. J.; Brothers, E.; Kudin, K. N.; Staroverov, V. N.; Kobayashi, R.; Normand, J.; Raghavachari, K.; Rendell, A.; Burant, J. C.; Iyengar, S. S.; Tomasi, J.; Cossi, M.; Rega, N.; Millam, N. J.; Klene, M.; Knox, J. E.; Cross, J. B.; Bakken, V.; Adamo, C.; Jaramillo, J.; Gomperts, R.; Stratmann, R. E.; Yazyev, O.; Austin, A. J.; Cammi, R.; Pomelli, C.; Ochterski, J. W.; Martin, R. L.; Morokuma, K.; Zakrzewski, V. G.; Voth, G. A.; Salvador, P.; Dannenberg, J. J.; Dapprich, S.; Daniels, A. D.; Farkas, Ö.; Foresman, J. B.; Ortiz, J. V.; Cioslowski, J.; Fox, D. J. , Gaussian, Inc., Wallingford CT, 2009, vol. Revision D.01.

38. G. Sheldrick, Acta Crystallographica Section A, 2008, 64, 112-122.

39. G. M. Sheldrick, Acta Crystallographica. Section C, Structural Chemistry, 2015, 71, 3-8.

40. A. Spek, Acta Crystallographica Section D, 2009, 65, 148-155.

41. A. Altomare, M. C. Burla, M. Camalli, G. L. Cascarano, C. Giacovazzo, A. Guagliardi, A. G. G. Moliterni, G. Polidori and R. Spagna, Journal of Applied Crystallography, 1999, 32, 115-119.

42. L. Farrugia, Journal of Applied Crystallography, 2012, 45, 849-854.

43. P. Van der Sluis and A. L. Spek, Acta Crystallographica Section A, 1990, 46, $194-$ 201. 
44. S. Westrip, Journal of Applied Crystallography, 2010, 43, 920-925.

45. K. Nakamoto, in Infrared and Raman Spectra of Inorganic and Coordination Compounds, John Wiley \& Sons, Inc., 2008, DOI: 10.1002/9780470405888.ch1, pp. 1-273.

46. R. L. Redington and K. C. Lin, Spectrochimica Acta Part A: Molecular Spectroscopy, 1971, 27, 2445-2460.

47. S. P. Gejji, K. Hermansson and J. Lindgren, The Journal of Physical Chemistry, 1993, 97, 3712-3715.

48. J. J. Peron, P. Saumagne and J. M. Lebas, Spectrochimica Acta Part A: Molecular Spectroscopy, 1970, 26, 1651-1666.

49. P. Molina, A. Arques and I. Cartagena, in Comprehensive Heterocyclic Chemistry III, eds. C. A. Ramsden, E. F. V. Scriven and R. J. K. Taylor, Elsevier, Oxford, 2008, DOI: http://dx.doi.org/10.1016/B978-008044992-0.00309-6, pp. 625-739.

50. C. R. Groom and F. H. Allen, Angewandte Chemie International Edition, 2014, 53, 662-671.

51. M. A. Halcrow, Dalton Transactions, 2003, DOI: 10.1039/B309242A, 4375-4384.

52. T. Hirschfeld, Appl. Opt., 1976, 15, 2965-2966.

53. J. D. Dunitz, V. Schomaker and K. N. Trueblood, The Journal of Physical Chemistry, 1988, 92, 856-867.

54. E. I. Tsyganova and L. M. Dyagileva, Russian Chemical Reviews, 1996, 65, 315.

55. K. H. Ohrbach, G. Radhoff and A. Kettrup, Journal of thermal analysis, 1983, 28, 155-159.

56. K. J. Eisentraut and R. E. Sievers, Journal of Inorganic and Nuclear Chemistry, 1967, 29, 1931-1936.

57. Y. Liu, J. Guo, R. Liu, Q. Wang, X. Jin, L. Ma, W. Lv, S. Liu, S. Yuan and H. Zhu, Journal of Luminescence, 2015, 157, 249-256.

58. J. Wang, Y.-Q. Fang, G. S. Hanan, F. Loiseau and S. Campagna, Inorganic Chemistry, 2005, 44, 5-7.

59. A. F. Orchard, Magnetochemistry, Oxford University Press Inc., New York, 2003.

60. B. N. Figgis, Introduction to Ligand Fields, Ed. Interscience Publishers, New York, 1966.

61. B. Bleaney and K. D. Bowers, Proceedings of the Royal Society of London A: Mathematical, Physical and Engineering Sciences, 1952, 214, 451-465.

62. O.Kahn, Molecular Magnetism, Willey-VCH, New York, 1993.

63. O. Kahn, Angewandte Chemie International Edition in English, 1985, 24, 834-850.

64. E. Ruiz, P. Alemany, S. Alvarez and J. Cano, Journal of the American Chemical Society, 1997, 119, 1297-1303.

65. E. Ruiz, P. Alemany, S. Alvarez and J. Cano, Inorganic Chemistry, 1997, 36, 36833688 .

\section{Highlights}

* The molecular structure of four coordination polymers $\mathrm{Cu}(4 \text {-stpy)(hfacac) })_{2}$ (I), $\mathrm{Cu}$ (4-qtpy)(hfacac) $)_{2}$ (II), $\mathrm{Cu}$ (3-qtpy)(hfacac) $)_{2}$ (III) and $\mathrm{Cu}$ (4-cntpy)(hfacac) $)_{2}$ (IV) has been established. 
- Molecular structure was discussed based on Single Crystal X-Ray Diffraction Studies and DFT calculations.

* Thermal stability was established for these compounds through TGA and DTG analysis.

* Vibrational and electronic study of these compounds was performed aided by theoretical calculus (DFT model) and contrasted with the experimental data.

* Magnetic and luminescent properties have been discussed. 